\title{
Habitat-based spatial models of cetacean density in the eastern Pacific Ocean
}

\author{
Karin A. Forney ${ }^{1, *}$, Megan C. Ferguson ${ }^{2,3}$, Elizabeth A. Becker ${ }^{1}$, Paul C. Fiedler ${ }^{3}$, \\ Jessica V. Redfern ${ }^{3}$, Jay Barlow ${ }^{3}$, Ignacio L. Vilchis ${ }^{3}$, Lisa T. Ballance ${ }^{3}$ \\ ${ }^{1}$ Protected Resources Division, Southwest Fisheries Science Center, National Marine Fisheries Service, \\ National Oceanic and Atmospheric Administration, Santa Cruz, California 95060, USA \\ ${ }^{2}$ National Marine Mammal Laboratory, Alaska Fisheries Science Center, National Marine Fisheries Service, \\ National Oceanic and Atmospheric Administration, Seattle, Washington 98115, USA \\ ${ }^{3}$ Protected Resources Division, Southwest Fisheries Science Center, National Marine Fisheries Service, \\ National Oceanic and Atmospheric Administration, La Jolla, California 92037, USA
}

\begin{abstract}
Many users of the marine environment (e.g. military, seismic researchers, fisheries) conduct activities that can potentially harm cetaceans. In the USA, Environmental Assessments or Environmental Impact Statements evaluating potential impacts are required, and these must include information on the expected number of cetaceans in specific areas where activities will occur. Typically, however, such information is only available for broad geographic regions, e.g. the entire West Coast of the United States. We present species-habitat models that estimate finer scale cetacean densities within the eastern Pacific Ocean. The models were developed and validated for 22 species or species groups, based on 15 large-scale shipboard cetacean and ecosystem assessment surveys conducted in the temperate and tropical eastern Pacific during the period from 1986 to 2006. Model development included consideration of different modeling frameworks, spatial and temporal resolutions of input variables, and spatial interpolation techniques. For the final models, expected group encounter rate and group size were modeled separately, using generalized additive models, as functions of environmental predictors, including bathymetry, distance to shore or isobaths, sea surface temperature (SST), variance in SST, salinity, chlorophyll, and mixed-layer depth. Model selection was performed using cross-validation on novel data. Smoothed maps of species density (and variance therein) were created from the final models for the California Current Ecosystem and eastern tropical Pacific Ocean. Model results were integrated into a web-interface that allows end-users to estimate densities for specified areas and provides fine-scale information for marine mammal assessments, monitoring, and mitigation.
\end{abstract}

KEY WORDS: Cetacean - Habitat - Spatial density model - Distribution - Pacific Ocean · Generalized additive model

\section{INTRODUCTION}

Under United States law, entities engaged in marine activities that can potentially harm marine mammals are required to complete Environmental Assessments and Environmental Impact Statements to determine the likely impact of their activities.
These documents specifically require an estimate of the number of animals that might be harmed or disturbed. A key element of this estimation is knowledge of cetacean (whale, dolphin, and porpoise) densities in specific areas where those activities will occur. Cetacean densities are typically estimated by line-transect surveys or mark-recapture studies (e.g. 
Hammond et al. 2002, Stevick et al. 2003, Gerrodette \& Forcada 2005, Barlow \& Forney 2007) across broad geographic areas, such as waters within the United States Exclusive Economic Zone off California, Oregon, and Washington, or the eastern tropical Pacific (ETP). These areas tend to be much larger than operational areas where impacts might occur (e.g. the Navy's Southern California Offshore Range off San Clemente Island), and finer scale estimates of cetacean density are required. Advances in cetaceanhabitat modeling allow predictions of cetacean densities on a finer spatial scale than traditional linetransect analyses, because cetacean densities are estimated as continuous functions of habitat variables (i.e. sea-surface temperature, seafloor depth, distance from shore, prey density, etc.) (Redfern et al. 2006). The objectives of the present study were: (1) to determine relationships between properties of the physical, biological, and chemical ocean environment and the distribution and abundance of cetaceans and (2) to develop spatial predictions of the distribution and abundance of cetaceans based on ecological factors, habitat, and other aspects of their natural behavior.

To meet these objectives, we used data from 15 ship-based cetacean and ecosystem assessment surveys to develop habitat models and predict density for 11 cetacean species and 1 species guild in the California Current Ecosystem (CCE) and for 14 species, subspecies, or genera in the ETP. All data used for modeling were collected by the National Oceanic and Atmospheric Administration's (NOAA) Southwest Fisheries Science Center (SWFSC) between 1986 and 2003 using accepted, peer-reviewed line-transect survey methods (Buckland et al. 2001) aboard large oceanographic vessels. Models were validated based on additional SWFSC surveys conducted during summer through fall of 2005 (CCE) and 2006 (ETP).

Methodological choices were required for various aspects of the modeling, including choice of statistical tools, sources of habitat data (in situ or remotely sensed), selection of temporal and spatial scales for models and input data, and evaluation of data interpolation techniques. In completing this project, we explored several of these choices using one or both data sets (ETP and CCE) to evaluate the effects on the resulting models. Some aspects of these analyses have already been published elsewhere (Becker 2007, Redfern et al. 2008, Barlow et al. 2009, Becker et al. 2010); in this paper we provide an overview of the entire project and the best-and-final models for the CCE and ETP. Final models for each region incorporated the respective methodological choices evalu- ated for that region; thus, the final modeling methodology differed slightly between the ETP and CCE. Model results have been collaboratively incorporated into a web-based system developed by Duke University (see Best et al. unpubl.). The software, called the Spatial Decision Support System (SDSS), allows users to view model outputs within areas of interest as color-coded maps of cetacean density, along with a table of densities and measures of precision (expressed as point-wise standard errors and lognormal $90 \%$ confidence intervals).

\section{MATERIALS AND METHODS}

\section{Cetacean survey data}

We base our habitat models on 15 cetacean and ecosystem assessment surveys conducted by SWFSC in the ETP and CCE during summer and fall of 1986 to 2006 and including $>17000$ sightings of cetacean groups and $>400000 \mathrm{~km}$ of transect coverage within the 2 study areas combined (Fig. 1, see Hamilton et al. 2009 for details on transect lines and sighting locations by species for 1986 to 2005). Rigorous line-transect methods were consistently used on all of these surveys (see Wade \& Gerrodette 1993, Gerrodette \& Forcada 2005, Barlow \& Forney 2007 for methodological details). Typically, a team of 6 trained observers searched for cetaceans from the ship's flying bridge, rotating among 3 observation stations (left $25 \times$ binoculars, data recorder, and right $25 \times$ binoculars) and alternating $2 \mathrm{~h}$ watches with $2 \mathrm{~h}$ of rest. The recorder searched with the naked eye (and occasionally $7 \times$ binoculars) and recorded effort, sighting, and environmental data on a computer. Sightings of all cetacean species were recorded on every survey. Surveys were mostly conducted in closing mode (Barlow \& Forney 2007), diverting from the trackline as needed to estimate group size and confirm species identification. On-duty observers estimated total group size and the percentage of each species independently; these were later averaged for each encounter.

In preparation for building the models, the cetacean survey data were divided into continuous-effort segments of approximately $10 \mathrm{~km}$ (ETP) or $5 \mathrm{~km}$ (CCE), as described in Becker et al. (2010). Each segment was assigned species-specific sighting information (number of encounters, mean group size) and environmental data as described below (see 'Habitat variables'), based on the midpoint of each segment. Twelve species or species groups were encountered sufficiently frequently to develop CCE models: striped 

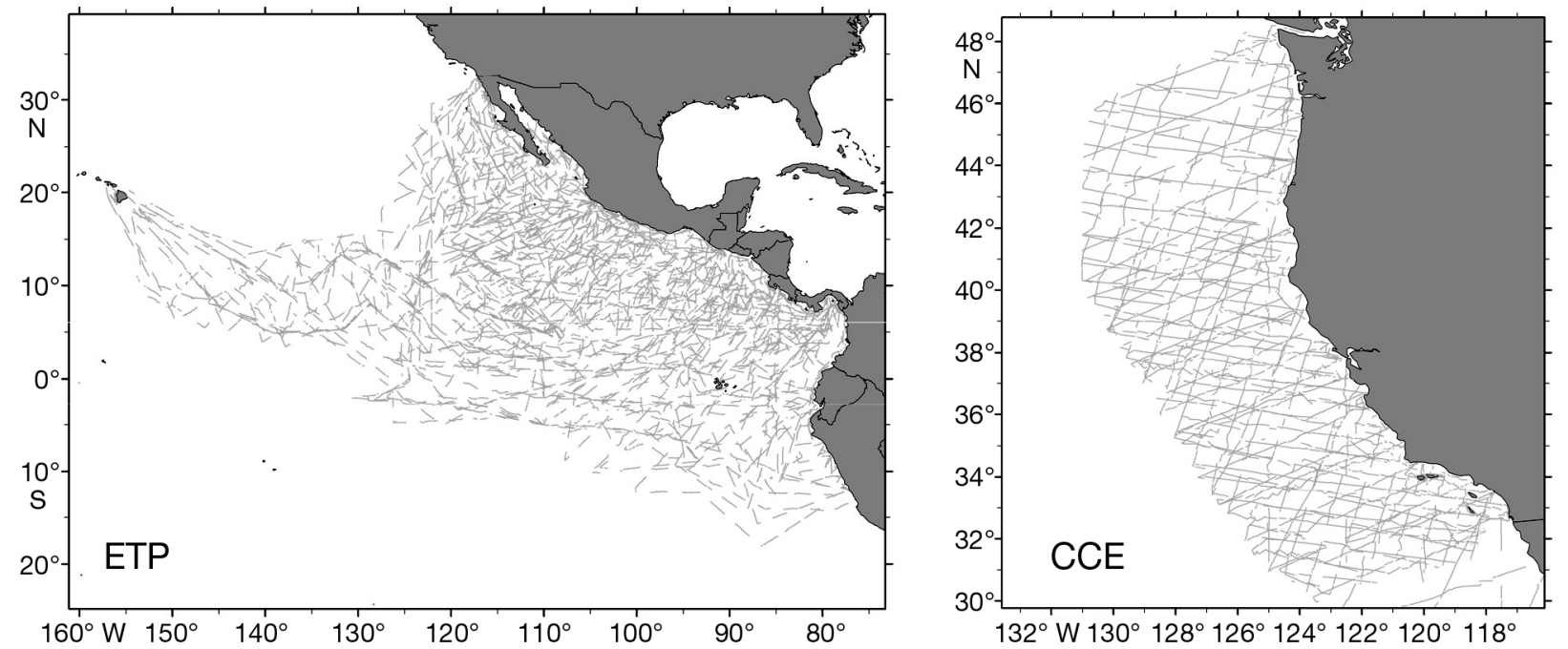

Fig. 1. Transects (gray lines) surveyed for cetaceans in the eastern tropical Pacific (ETP) during 1986, 1987, 1988, 1989, 1990, 1998, 1999, 2000, 2003, and 2006, and in the California Current Ecosystem (CCE) during 1991, 1993, 1996, 2001, and 2005

dolphin Stenella coeruleoalba, short-beaked common dolphin Delphinus delphis, Risso's dolphin Grampus griseus, Pacific white-sided dolphin Lagenorhynchus obliquidens, northern right whale dolphin Lissodelphis borealis, Dall's porpoise Phocoenoides dalli, sperm whale Physeter macrocephalus, fin whale Balaenoptera physalus, blue whale $B$. musculus, humpback whale Megaptera novaeangliae, Baird's beaked whale Berardius bairdii, and a small beaked whale guild (including Cuvier's beaked whale, Ziphius cavirostris, and beaked whales of the genus Mesoplodon). In the ETP, models could be developed for 10 species, 3 subspecies, and 1 genus: offshore pantropical spotted dolphin Stenella attenuata attenuata, eastern spinner dolphin $S$. longirostris orientalis, whitebelly spinner dolphin $S$. longirostris longirostris, striped dolphin, rough-toothed dolphin Steno bredanensis, short-beaked common dolphin, common bottlenose dolphin Tursiops truncatus, Risso's dolphin, shortfinned pilot whale Globicephala macrorhynchus, dwarf sperm whale Kogia sima, Cuvier's beaked whale, Mesoplodon beaked whales, blue whale, and Bryde's whale Balaenoptera edeni. Models for offshore pantropical spotted dolphins were, however, based only on the 1998 to 2003 surveys because the transect lines for this survey period were optimized to estimate the abundance of the offshore form.

\section{Habitat variables}

Water depth was derived from the ETOPO2 2-min global relief data (U.S. Department of Commerce
2006). Bathymetric slope was calculated as the magnitude of the bathymetry gradient using the gradient operator tool in Generic Mapping Tools (Wessel \& Smith 1998). Depth and slope values for each geographic location were obtained using the 'sample' tool in ArcGIS (Version 9.2, ESRI). Sea-surface temperature (SST) and salinity (SSS) from a thermosalinograph were recorded continuously at 0.5 to 2 min intervals. Mixed-layer depth (MLD, the depth at which temperature is $0.5^{\circ} \mathrm{C}$ less than surface temperature; Monterey \& Levitus 1997) was estimated from expendable bathythermograph (XBT) and conductivity-temperature-depth (CTD) casts collected 3 to 5 times per day. Surface chlorophyll (CHL, mg $\mathrm{m}^{-3}$ ) was estimated at the same stations from the surface bottle on the CTD or from bucket samples analyzed by standard techniques (Holm-Hansen et al. 1965). Details of the field methods can be found in Philbrick et al. $(2001,2003)$.

Given the generally larger scale oceanic processes within the ETP (Fiedler \& Talley 2006), and that analyses suggest larger scale cetacean-habitat models are appropriate for this study area (Redfern et al. 2008), values of the habitat variables for model development were calculated as weighted averages of the oceanographic data collected on the same day and within a radius of $50 \mathrm{~km}$ of each segment midpoint. Inverse distance weighting $\left(\right.$ distance $^{-1}$ ) was used in the weighted average computations. Within the CCE, in contrast, spatial scales of habitat variability are smaller, due to coastal processes and the effect of latitude on eddy scale (Longhurst 2007); therefore, alternate methods of estimating location-specific val- 
ues for each segment were used. The underway thermosalinograph data (SST, SSS) were averaged within a $5 \mathrm{~km}$ radius of each segment midpoint.

In the CCE, we used interpolation of all oceanographic measurements to obtain continuous spatial grids of our in situ oceanographic habitat variables. Interpolation inevitably introduces errors caused by spatial gaps between sample points and measurement inaccuracy and imprecision. The best estimate of an independent variable at an unsampled point in space (and time) is derived from an interpolation of sampled data that minimizes both the influence of measurement or sampling error in the observations and error introduced by the statistical technique, either between observations or at edges. To determine the optimal interpolation method to use for estimating habitat variables, 5 smoothing interpolation methods were compared for 3 variables (SST, thermocline depth [depth of maximum temperature gradient in a $10 \mathrm{~m}$ interval, which is highly correlated with MLD] and CHL) from the 2005 CCE survey, using the program Surfer (Golden Software, Version 2008): inverse distance squared, kriging, local polynomial, radial basis function, and minimum curvature.

For each variable, subsets of observations were selected and removed from the dataset, the remaining observations were interpolated, and the residuals of the omitted observations were calculated, where the residual is the difference between an omitted data value and the interpolated value (i.e. the predicted value) at that point. Two jackknife procedures were used to calculate the mean and standard deviation of residuals at each data point: (1) single (omit each observation one at a time) and (2) daily (omit each shipday, typically with 5 observations, 1 ship-day at a time). In general, the only resultant difference between these 2 procedures was that daily jackknife residuals were slightly greater than single jackknife residuals. For each variable, a variogram analysis estimated length scale (i.e. how rapidly variance changes with increased distance between sampling points), error variance or the nugget effect (this source of error can be due to measurement error or small-scale heterogeneity in the system), and anisotropy. Then, jackknifing and interpolation were performed with similar search parameters for each of the 5 interpolation methods (see Barlow et al. 2009 for details). Grid resolution was 1 degree of latitude and longitude. Using the optimal interpolation method, yearly interpolations were created for 5 CCE surveys (1991, 1993, 1996, 2001, and 2005). Values of CHL and MLD for each segment midpoint were subsequently estimated from the interpolated yearly fields using Surfer's resi- dual command. Chlorophyll values were log-transformed in each ecosystem because the minimum and maximum values differed by an order of magnitude.

In addition to the in situ measurements, some remotely sensed data sources were considered in the CCE models. SST (taken from NOAA/National Environmental Satellite, Data, and Information Service/ Pathfinder V5) and measures of its variance at species-specific spatial scales were included as potential predictors, using 8 d running average SST composites (Becker et al. 2010). Although past studies have shown relationships between cetacean sightings and other remotely sensed measures, such as chlorophyll (Smith et al. 1986, Jaquet et al. 1996, Moore et al. 2002), satellite-derived measures of chlorophyll concentration were not consistently available for the survey periods in the present study. Remotely sensed data at various spatial and temporal scales have previously been compared to in situ data within the CCE to identify the spatial scales with the best predictive power (Becker et al. 2010). In the present study, we selected CCE models with the best predictive ability from 1 of 2 options: remotely sensed (at the scales described in Becker et al. 2010), or a combined set of in situ and remotely sensed predictor variables. The latter included the predictors used in the remotely sensed models, as well as in situ values of CHL and MLD estimated from the interpolated yearly fields, and SSS underway thermosalinograph data averaged within a $5 \mathrm{~km}$ radius of each segment midpoint. Remotely sensed measures of SST and CV(SST) were used in the combined models because remotely sensed CV(SST) was found to be more effective at characterizing frontal regions than our in situ CV(SST) measures, and SST measures performed similarly (Becker et al. 2010).

\section{Model framework}

Cetacean population density predictions were derived from encounter rate and group size models developed within a generalized additive modeling framework developed by Hedley et al. (1999) and Ferguson et al. (2006a,b). Generalized additive models (GAMs) are commonly used to relate characteristics of a species, such as distribution or abundance, to environmental characteristics. A GAM may be represented as:

$$
g(\mu)=\alpha+\sum_{j=1}^{p} f_{j}\left(X_{j}\right)
$$

(Hastie \& Tibshirani 1990). The function $g(\mu)$ is known as the link function, and it relates the mean of 
the response variable given the predictor variables $\mu=E\left(Y \mid X_{1}, \ldots, X_{p}\right)$ to the additive predictor $\alpha+\Sigma_{j} f_{j}\left(X_{j}\right)$. GAMs are nonparametric extensions of generalized linear models (GLMs). The components $f_{j}\left(X_{j}\right)$ in the additive predictor of a GAM may include nonparametric smooth functions of the predictor variables, whereas a GLM is composed of a linear predictor, $\alpha+\Sigma_{j} \beta_{j} X_{j}$, in which the terms $\beta_{j}$ are constants. This difference between the additive and linear predictor allows GAMs to be more flexible than GLMs.

The CCE models developed in the present study used S-PLUS (Version 6) for model development, building upon the methods used in previous modeling studies for this area (Forney 2000, Becker 2007). Alternate algorithms for constructing GAMs and GLMs were separately evaluated for the ETP only, using a common set of environmental and cetacean line-transect survey data. Three different algorithms for constructing GAMs and 1 for constructing GLMs were included in the comparison: (1) S-PLUS gam with cubic smoothing splines and up to 3 degrees of freedom (df), (2) R (version 2.6.2) gam from package gam with cubic smoothing splines and up to $3 \mathrm{df}$, (3) R (version 2.6.2) $\mathrm{glm}$ from package stats with polynomial terms of up to $3 \mathrm{df}$ to allow a degree of non-linearity between predictor and response variables, and (4) R (version 2.6.2) gam from package mgcv (version 1.3-29) using cubic regression splines and thin-plate regression splines with shrinkage. For the first 3 algorithms used in the ETP analysis, forward/backward stepwise variable selection was implemented using step.gam and Akaike's information criterion (AIC). In contrast, the mgcv gam determines the effective $\mathrm{df}$ for the smoothing parameter by minimizing the generalized cross validation (GCV) score (Wood 2006) using a selection of numerical optimization methods. We tested a total of 6 different numerical method options, 4 to construct the encounter rate models (outer, perf.outer, perf.magic, and perf.mgcv) and 2 to construct the group size models (magic and mgcv). Because GCV is known to overfit on occasion (Kim \& Gu 2004), we tested 2 values of the parameter gamma that mgcv uses to compute GCV. Larger values for gamma penalize model complexity more than smaller values, so we tested the default, gamma $=$ 1.0 , and an alternative, gamma $=1.4$.

\section{Encounter rate and group size models}

The number of cetacean sightings per kilometer of survey effort (encounter rate) was modeled for all transect segments using a quasi-likelihood model with variance proportional to the mean and a logarithmic link function. The natural logarithm of segment length was included as an offset term to standardize each sample for effort because some segments were slightly longer or shorter than the 5 or $10 \mathrm{~km}$ target length. Group sizes varied over 3 orders of magnitude and were modeled with the natural logarithm of group size as the response variable and an identity link function, using only segments that contained sightings. A ratio estimator was used to correct for back-transformation bias (Smith 1993) in group-size predictions prior to calculating densities using the standard line-transect formula and previously published values of $f(0)$ and $g(0)$ (Barlow 2003, Ferguson \& Barlow 2001):

$$
D=\left(\frac{n}{L}\right) \cdot S \cdot \frac{1}{2 \cdot \mathrm{ESW} \cdot g(0)}
$$

where $n / L$ is the encounter rate (number of sightings per unit length of transect), $S$ is the expected (or mean) group size, ESW is the effective strip width (1-sided), or $1 / f(0)$, where $f(0)$ is the sighting probability density at zero perpendicular distance, and $g(0)$ is the probability of detecting an animal on the transect line.

Potential predictor variables for encounter rate and group size models for the ETP included closest distance to shore (continents or islands), depth, and in situ oceanographic data collected during the linetransect surveys, specifically SST, SSS, MLD, and log-transformed values of CHL. Potential predictor variables for the CCE included distance to the $2000 \mathrm{~m}$ isobath, depth, slope, remotely sensed SST, $\mathrm{CV}$ (SST) (as a proxy for frontal regions), along-track SSS from the thermosalinograph, and estimates of MLD and CHL (log-transformed) derived from the interpolated in situ station data. In both regions, the average sea state (Beaufort scale) on each segment was included as a predictor in all models to account for potential biases due to changes in detection probability. Only survey effort conducted in sea states corresponding to Beaufort 5 or less was used to build the models, corresponding to the conditions under which $f(0)$ and $g(0)$ estimates were derived (see Barlow et al. 2009, Becker et al. 2010 for further details). Final density predictions were based on the average observed sea state during the surveys. Latitude and longitude were generally not included in the models because they are static predictors and can obscure patterns with correlated dynamic predictor variables, such as SST. The only exception was the eastern spinner dolphin, for which geographic coordinates provided a simple method of 
separating this subspecies from whitebelly spinner dolphins when the models' physical and biological habitat variables could not.

\section{Model selection}

Model validation using an independent data set is an integral part of building robust cetacean-habitat models (Forney 1997, 2000, Becker 2007). In the present analysis, final models for the CCE and ETP were selected using a 2-part process in which models were initially built based on the available SWFSC survey data through 2003. Candidate models were then evaluated in terms of their predictive capabilities when applied to data from the novel 2005 (CCE) and 2006 (ETP) SWFSC cetacean surveys. Predictions and overall model performance were compared to identify the best models, using explained deviance, average squared prediction error (ASPE), and ratios of observed to predicted densities for the entire study area. Density predictions derived from the encounter rate and group size models were also plotted on maps of the study area, and the spatial distribution was qualitatively evaluated by experts knowledgeable about cetacean ecology in the study areas. Following model selection and validation, the best models were then re-fit to include the additional year of data (2005 and 2006, respectively). For the CCE region, where standard line-transect density estimates for the same survey years have previously been made using the same estimates of $f(0)$ and $g(0)$ (Barlow 2003), we also compared the modeled study-area abundances to the standard line-transect estimates as a cross-check to validate model predictions. Although the estimates provided by Barlow (2003) also have uncertainty associated with them, they provide a benchmark against which our model predictions could be evaluated.

\section{Cetacean density interpolation}

The segment-specific predictions from the best models were interpolated to the entire ETP and CCE study areas using Surfer and inverse distance weighting to the power of 2 . This weighting method gives points closer to each grid node greater influence than those farther away. For the California Current models, interpolation grids were created at a resolution of $25 \mathrm{~km}$, and all data within a search radius of 2 degrees latitude $(222 \mathrm{~km})$ were used for interpolation, because transect spacing ranged from 150 to $230 \mathrm{~km}$ during the surveys, and contouring results were more robust when data from $>1$ transect line were included. For the ETP models, grids were developed at a resolution of $100 \mathrm{~km}$, and all data within a search radius of 10 degrees latitude $(1111 \mathrm{~km})$ were included in the inverse distance weighting calculations. After creating grids for each of the individual survey years, individual grid cells were averaged across all years to calculate a mean species density and its inter-annual variance. A final average density prediction grid was then re-calculated using a $5 \times 5$ pixel moving average filter with equal weight, to eliminate occasional over-specification ('bull's eye') effects. The complete gridding process thus provided smoothed multi-year average cetacean densities, taking into account both the varying oceanographic conditions and different levels of sampling coverage achieved during the SWFSC cetacean surveys. Standard errors and log-normal $90 \%$ confidence limits were calculated from the grid cell averages and variances using standard formulae.

\section{RESULTS}

\section{Oceanographic data interpolation}

Kriging was selected as the best method for interpolating the oceanographic data collected during the SWFSC surveys, based on its better performance and the prevalence of its use in geostatistical spatial mapping. Further, kriging allows patterns of variability in the data to be used directly through the fitted variogram model. Minimum curvature, radial basis function, and, to a lesser extent, inverse distance squared tended to produce isolated areas of high or low values (i.e. bull's eyes). Local polynomial interpolation tended to produce extreme highs or lows beyond the edge of the sampled area; this problem was minimized by using a first-order polynomial. Kriging resulted in the fewest number of bull's eyes but had slightly higher residuals. Nonetheless, residuals at individual sample points were very similar for all interpolation methods (e.g. $\mathrm{r}^{2}=0.94$ between single jackknife residuals of inverse distance squared and kriging methods, and $\mathrm{r}^{2}$ $=0.93$ and 0.99 between single and daily jackknife residuals for these 2 methods).

Yearly fields were created at the approximate resolution of station samples, (i.e. 0.5 degrees in the $\mathrm{CCE}$ ), and spline interpolation was subsequently used to produce finer scale interpolated fields at 0.05 degree resolution. This 2-step process was necessary because kriging directly at the finer scale created artifacts in areas of sparse coverage, and adjusting 
search parameters to avoid the artifacts resulted in the loss of mesoscale variability (100 to $200 \mathrm{~km}$ ) that might be important for habitat modeling. The final fields generated by the 2-step process were nearly identical to the original high-resolution fields but did not contain the previously described artifacts. The variogram analyses within the CCE typically gave cross-shore to alongshore anisotropy of 0.5 or less (i.e. variability was much greater when sampling from the coast to offshore compared to alongshore). The recommended anisotropy range is 0.5 to 2.0 , if the $x$ and $y$-axes have the same units; the use of anisotropy values of 0.5 or less estimated from the variogram resulted in overly smoothing the grids. Therefore, anisotropy was constrained to be at least 0.75 ; this resulted in a lower goodness-of-fit for the variogram model, but the interpolated surfaces were better representations of the spatial patterns in the data.

\section{Model algorithm comparison}

During the comparison of GAM algorithms using the ETP data, we found a previously unreported bug in the step.gam function from the R package gam that prevented step.gam from including the offset term for survey effort in any encounter rate model examined during the stepwise search. Therefore, our comparison of the gam algorithms in S-PLUS and the R package gam was limited to group size models, which did not have an offset term. Group size GAMs built using the gam algorithms in S-PLUS and the R package gam

Table 1. Comparison of the simple and complex encounter rate generalized additive models (GAMs) for the eastern tropical Pacific, built using the gam algorithm in the R package mgcv. The term gam.method refers to the numerical method used to optimize the smoothing parameter estimation criterion for the GAM. Splines were either cubic regression splines with shrinkage (cs) or thin-plate regression splines with shrinkage (ts). The gamma parameter determines the penalty for model complexity, with larger values of gamma resulting in greater penalty. Also shown are the total effective degrees of freedom (EDF), the sum of the absolute value of the deviance in the ratio of observed to predicted number of sightings (R), the explained deviance, and the average squared prediction error (ASPE) for the best model re-fit using all data from 1986 to 2006 (or 1998 to 2006 for pantropical spotted dolphins). If a single model clearly outperformed all others, the corresponding elements of the table show 'NA' for the type of model that was not considered any further

\begin{tabular}{|c|c|c|c|c|c|c|c|c|}
\hline Species & $\begin{array}{l}\text { Model } \\
\text { type }\end{array}$ & gam.method & Spline & gamma & $\begin{array}{l}\text { Total } \\
\text { EDF }\end{array}$ & $\mathrm{R}$ & $\begin{array}{c}\text { Explained } \\
\text { deviance }\end{array}$ & ASPE \\
\hline Pantropical spotted dolphin & Simple & perf.magic & CS & 1.4 & 6.914 & 1.443 & 0.104 & 0.044 \\
\hline Stenella attenuata attenuata & Complex & outer & ts & 1.0 & 42.143 & 1.303 & 0.116 & 0.044 \\
\hline Eastern spinner dolphin & Simple & perf.magic & CS & 1.0 & 32.200 & 1.947 & 0.252 & 0.018 \\
\hline Stenella longirostris orientalis & Complex & NA & NA & NA & NA & NA & NA & NA \\
\hline Whitebelly spinner dolphin & Simple & perf.magic & CS & 1.0 & 22.627 & 2.070 & 0.165 & 0.007 \\
\hline Stenella longirostris longirostris & Complex & NA & NA & NA & NA & NA & NA & NA \\
\hline Striped dolphin & Simple & perf.magic & $\mathrm{CS}$ & 1.0 & 22.533 & 1.149 & 0.086 & 0.048 \\
\hline Stenella coeruleoalba & Complex & outer & ts & 1.4 & 53.388 & 1.048 & 0.094 & 0.048 \\
\hline Rough-toothed dolphin & Simple & perf.magic & CS & 1.0 & 8.914 & 1.355 & 0.155 & 0.010 \\
\hline Steno bredanensis & Complex & outer & CS & 1.0 & 60.560 & 0.745 & 0.180 & 0.010 \\
\hline Short-beaked common dolphin & Simple & perf.magic & CS & 1.4 & 16.733 & 1.599 & 0.162 & 0.020 \\
\hline Delphinus delphis & Complex & perf.outer & CS & 1.0 & 59.646 & 1.494 & 0.183 & 0.020 \\
\hline Common bottlenose dolphin & Simple & perf.magic & ts & 1.4 & 14.240 & 1.806 & 0.163 & 0.029 \\
\hline Tursiops truncatus & Complex & perf.outer & ts & 1.0 & 51.457 & 1.475 & 0.178 & 0.029 \\
\hline Risso's dolphin & Simple & perf.magic & CS & 1.0 & 14.238 & 2.196 & 0.088 & 0.011 \\
\hline Grampus griseus & Complex & outer & CS & 1.0 & 59.795 & 1.797 & 0.111 & 0.011 \\
\hline Cuvier's beaked whale & Simple & perf.magic & CS & 1.0 & 7.027 & 2.023 & 0.056 & 0.005 \\
\hline Ziphius cavirostris & Complex & perf.magic & ts & 1.0 & 8.973 & 1.742 & 0.057 & 0.005 \\
\hline Blue whale & Simple & perf.magic & CS & 1.4 & 24.174 & 4.092 & 0.215 & 0.005 \\
\hline Balaenoptera musculus & Complex & NA & NA & NA & NA & NA & NA & NA \\
\hline Bryde's whale & Simple & perf.magic & ts & 1.0 & 10.284 & 1.697 & 0.058 & 0.012 \\
\hline Balaenoptera edeni & Complex & NA & NA & NA & NA & NA & NA & NA \\
\hline Short-finned pilot whale & Simple & perf.magic & CS & 1.0 & 16.160 & 1.715 & 0.061 & 0.014 \\
\hline Globicephala macrorhynchus & Complex & outer & ts & 1.4 & 57.162 & 1.625 & 0.086 & 0.014 \\
\hline Dwarf sperm whale & Simple & perf.outer & CS & 1.4 & 26.920 & 1.273 & 0.342 & 0.005 \\
\hline Kogia sima & Complex & outer & CS & 1.0 & 61.997 & 0.646 & 0.388 & 0.005 \\
\hline \multirow[t]{2}{*}{ Mesoplodon spp. } & Simple & perf.outer & CS & 1.0 & 52.296 & 1.736 & 0.140 & 0.005 \\
\hline & Complex & NA & NA & NA & NA & NA & NA & NA \\
\hline
\end{tabular}


were essentially identical: the best models contained the exact same predictor variables and associated df, and the parameterizations of the smoothing splines were identical, except for small differences that were likely due to the precision of the software platforms. GAMs built using the R package mgcv often resulted in different predictor variables, or different $\mathrm{df}$, than those built using S-PLUS. The mgcv gam algorithm allows users to adjust many more parameters and settings to build the models compared to the S-PLUS analogue. To the knowledgeable user, this flexibility enables fine-tuning of the GAMs. On the other hand, having numerous adjustable arguments makes the algorithm less user-friendly because more time must be invested to learn how to build appropriate models.

Tables $1 \& 2$ show the range of encounter rate and group size models, respectively, selected as the final model by mgcv gam given the specified combination of settings for the gam.method, smoothing spline, and gamma arguments. The 'simple models' had relatively few effective df and the smallest sum of abso- lute deviations of the observed-to-predicted ratios. The 'complex models' had relatively large effective df in addition to good agreement between observed and predicted values of the response variable. When cetacean experts were shown geographic contour plots of the predictions from the competing simple and complex mgcv gam models for each species, the simple models were overwhelmingly preferred to the complex models. The dominant criticisms of the complex models were 2-fold: the predictions from the complex models either (1) exhibited relatively smallscale details in population density that are unexplainable given existing knowledge of the dynamics of the ecosystem, or (2) were nearly identical to those from the simple model, and, therefore, the extra model complexity was not necessary for capturing the spatial patterns.

With mgcv, encounter rate models using gam. method $=$ perf.magic produced simple models with the greatest predictive performance. The best complex encounter rate models were developed using

Table 2. Comparison of the simple and complex group size generalized additive models for the eastern tropical Pacific, built using the gam algorithm in the R package mgcv (for further details of methods and taxonomic names see 'Model framework' and Table 1)

\begin{tabular}{|c|c|c|c|c|c|c|c|c|}
\hline Species & $\begin{array}{l}\text { Model } \\
\text { type }\end{array}$ & gam.method & Spline & gamma & $\begin{array}{l}\text { Total } \\
\text { EDF }\end{array}$ & $\mathrm{R}$ & $\begin{array}{c}\text { Explained } \\
\text { deviance }\end{array}$ & ASPE \\
\hline Pantropical spotted dolphin & $\begin{array}{l}\text { Simple } \\
\text { Complex }\end{array}$ & $\begin{array}{l}\text { magic } \\
\text { NA }\end{array}$ & $\begin{array}{l}\text { Cs } \\
\text { NA }\end{array}$ & $\begin{array}{l}1.4 \\
\text { NA }\end{array}$ & $\begin{array}{l}3.830 \\
\text { NA }\end{array}$ & $\begin{array}{l}1.663 \\
\text { NA }\end{array}$ & $\begin{array}{c}0.038 \\
\text { NA }\end{array}$ & $\begin{array}{c}6734.449 \\
\text { NA }\end{array}$ \\
\hline Eastern spinner dolphin & $\begin{array}{l}\text { Simple } \\
\text { Complex }\end{array}$ & $\begin{array}{l}\text { magic } \\
\text { mgcv }\end{array}$ & $\begin{array}{l}\text { ts } \\
\text { CS }\end{array}$ & $\begin{array}{l}1.4 \\
1.0\end{array}$ & $\begin{array}{l}13.222 \\
21.621\end{array}$ & $\begin{array}{l}2.161 \\
1.992\end{array}$ & $\begin{array}{l}0.105 \\
0.150\end{array}$ & $\begin{array}{l}12863.707 \\
12517.964\end{array}$ \\
\hline Whitebelly spinner dolphin & $\begin{array}{l}\text { Simple } \\
\text { Complex }\end{array}$ & $\begin{array}{l}\text { magic } \\
\text { NA }\end{array}$ & $\begin{array}{l}\text { ts } \\
\text { NA }\end{array}$ & $\begin{array}{l}1.0 \\
\text { NA }\end{array}$ & $\begin{array}{l}1.783 \\
\text { NA }\end{array}$ & $\begin{array}{l}0.776 \\
\text { NA }\end{array}$ & $\begin{array}{l}0.083 \\
\text { NA }\end{array}$ & $\begin{array}{c}41435.168 \\
\text { NA }\end{array}$ \\
\hline Striped dolphin & $\begin{array}{c}\text { Simple } \\
\text { Complex }\end{array}$ & $\begin{array}{l}\text { magic } \\
\text { mgcv }\end{array}$ & $\begin{array}{l}\text { ts } \\
\text { ts }\end{array}$ & $\begin{array}{l}1.4 \\
1.0\end{array}$ & $\begin{array}{l}12.641 \\
17.934\end{array}$ & $\begin{array}{l}0.543 \\
0.473\end{array}$ & $\begin{array}{l}0.089 \\
0.098\end{array}$ & $\begin{array}{l}2898.201 \\
2890.072\end{array}$ \\
\hline Rough-toothed dolphin & $\begin{array}{l}\text { Simple } \\
\text { Complex }\end{array}$ & $\begin{array}{l}\text { magic } \\
\text { NA }\end{array}$ & $\begin{array}{l}\text { ts } \\
\text { NA }\end{array}$ & $\begin{array}{l}1.4 \\
\text { NA }\end{array}$ & $\begin{array}{l}6.789 \\
\text { NA }\end{array}$ & $\begin{array}{l}1.672 \\
\text { NA }\end{array}$ & $\begin{array}{c}0.148 \\
\text { NA }\end{array}$ & $\begin{array}{l}114.062 \\
\text { NA }\end{array}$ \\
\hline Short-beaked common dolphin & $\begin{array}{l}\text { Simple } \\
\text { Complex }\end{array}$ & $\begin{array}{l}\text { magic } \\
\text { magic }\end{array}$ & $\begin{array}{l}\text { Cs } \\
\text { ts }\end{array}$ & $\begin{array}{l}1.4 \\
1.0\end{array}$ & $\begin{array}{l}10.974 \\
21.745\end{array}$ & $\begin{array}{l}1.627 \\
1.094\end{array}$ & $\begin{array}{l}0.138 \\
0.215\end{array}$ & $\begin{array}{l}83237.681 \\
77358.863\end{array}$ \\
\hline Common bottlenose dolphin & $\begin{array}{l}\text { Simple } \\
\text { Complex }\end{array}$ & $\begin{array}{l}\text { magic } \\
\text { mgcv }\end{array}$ & $\begin{array}{l}\text { ts } \\
\text { CS }\end{array}$ & $\begin{array}{l}1.4 \\
1.0\end{array}$ & $\begin{array}{l}10.162 \\
27.789\end{array}$ & $\begin{array}{l}1.183 \\
1.292\end{array}$ & $\begin{array}{l}0.060 \\
0.118\end{array}$ & $\begin{array}{l}12433.442 \\
12461.770\end{array}$ \\
\hline Risso's dolphin & $\begin{array}{l}\text { Simple } \\
\text { Complex }\end{array}$ & $\begin{array}{l}\text { magic } \\
\text { magic }\end{array}$ & $\begin{array}{l}\text { ts } \\
\text { CS }\end{array}$ & $\begin{array}{l}1.4 \\
1.0\end{array}$ & $\begin{array}{r}5.031 \\
20.570\end{array}$ & $\begin{array}{l}0.570 \\
0.294\end{array}$ & $\begin{array}{l}0.096 \\
0.208\end{array}$ & $\begin{array}{l}353.787 \\
304.655\end{array}$ \\
\hline Cuvier's beaked whale & $\begin{array}{l}\text { Simple } \\
\text { Complex }\end{array}$ & $\begin{array}{l}\text { magic } \\
\text { mgcv }\end{array}$ & $\begin{array}{l}\text { ts } \\
\text { CS }\end{array}$ & $\begin{array}{l}1.0 \\
1.0\end{array}$ & $\begin{array}{l}10.324 \\
16.626\end{array}$ & $\begin{array}{l}0.543 \\
0.621\end{array}$ & $\begin{array}{l}0.217 \\
0.202\end{array}$ & $\begin{array}{l}1.138 \\
1.185\end{array}$ \\
\hline Blue whale & $\begin{array}{l}\text { Simple } \\
\text { Complex }\end{array}$ & $\begin{array}{l}\text { magic } \\
\text { magic }\end{array}$ & $\begin{array}{l}\text { ts } \\
\text { CS }\end{array}$ & $\begin{array}{l}1.4 \\
1.0\end{array}$ & $\begin{array}{r}7.571 \\
33.089\end{array}$ & $\begin{array}{l}0.737 \\
0.324\end{array}$ & $\begin{array}{l}0.300 \\
0.586\end{array}$ & $\begin{array}{l}2.469 \\
1.519\end{array}$ \\
\hline Bryde's whale & $\begin{array}{l}\text { Simple } \\
\text { Complex }\end{array}$ & $\begin{array}{l}\text { magic } \\
\text { NA }\end{array}$ & $\begin{array}{l}\text { ts } \\
\text { NA }\end{array}$ & $\begin{array}{l}1.0 \\
\text { NA }\end{array}$ & $\begin{array}{l}6.194 \\
\text { NA }\end{array}$ & $\begin{array}{l}0.705 \\
\text { NA }\end{array}$ & $\begin{array}{c}0.073 \\
\text { NA }\end{array}$ & $\begin{array}{l}1.108 \\
\text { NA }\end{array}$ \\
\hline Short-finned pilot whale & $\begin{array}{l}\text { Simple } \\
\text { Complex }\end{array}$ & $\begin{array}{l}\text { magic } \\
\text { magic }\end{array}$ & $\begin{array}{l}\text { ts } \\
\text { CS }\end{array}$ & $\begin{array}{l}1.0 \\
1.0\end{array}$ & $\begin{array}{r}5.428 \\
11.473\end{array}$ & $\begin{array}{l}1.080 \\
1.391\end{array}$ & $\begin{array}{l}0.059 \\
0.117\end{array}$ & $\begin{array}{l}261.772 \\
248.580\end{array}$ \\
\hline Dwarf sperm whale & $\begin{array}{l}\text { Simple } \\
\text { Complex }\end{array}$ & $\begin{array}{l}\text { magic } \\
\text { mgcv }\end{array}$ & $\begin{array}{l}\text { ts } \\
\text { CS }\end{array}$ & $\begin{array}{l}1.4 \\
1.0\end{array}$ & $\begin{array}{r}1.847 \\
18.484\end{array}$ & $\begin{array}{l}1.368 \\
1.118\end{array}$ & $\begin{array}{l}0.051 \\
0.330\end{array}$ & $\begin{array}{l}1.343 \\
0.977\end{array}$ \\
\hline Mesoplodon spp. & $\begin{array}{l}\text { Simple } \\
\text { Complex }\end{array}$ & $\begin{array}{l}\text { magic } \\
\text { mgcv }\end{array}$ & $\begin{array}{l}\text { ts } \\
\text { ts }\end{array}$ & $\begin{array}{l}1.0 \\
1.0\end{array}$ & $\begin{array}{r}9.422 \\
14.329\end{array}$ & $\begin{array}{l}0.763 \\
0.768\end{array}$ & $\begin{array}{l}0.238 \\
0.274\end{array}$ & $\begin{array}{l}0.678 \\
0.653\end{array}$ \\
\hline
\end{tabular}


outer (6 models), perf.outer (4 models), and perf. magic (2 models). Cubic regression splines were preferred for simple encounter rate models, whereas the complex models were constructed using either cubic or thin-plate regression splines. Simple models were split almost equally between those built using gamma $=1.0$ (8 models) and 1.4 (6 models), while the best complex models were generally constructed using gamma $=1.0$. For group size models, the gam.method magic produced the simple models with the greatest predictive performance, while the best complex models were divided among gam.methods mgcv and magic. Preferred simple models were generally constructed using thin-plate regression splines, whereas cubic regression splines were selected more frequently in the complex models. The majority of simple models were constructed using gamma $=1.4$, and most complex models used the default value of 1.0.
The differences between GLMs and S-PLUS GAMs for a given dataset were surprisingly small based on a comparison of ASPE, explained deviance, the predictor variables and associated $\mathrm{df}$ in the final models, the shape of the smoothing splines for each predictor variable, and visual examination of geographic contour plots of predicted density. Greater differences in statistical details (but not in geographic contour plots of predicted densities) were observed between GLMs and GAMs constructed using mgcv, because the GLMs and SPLUS GAMs were constrained to a maximum of $3 \mathrm{df}$ per term, whereas the mgcv gam function allowed higher df. However, as evident from the comparison between simple and complex mgcv gam models in Tables $1 \& 2$ and the outcome of the cetacean experts' review, greater complexity frequently did not result in better models.

Table 3. California Current Ecosystem model summary of explained deviance (exp. dev.), average squared prediction error (ASPE), and predictor variables included in the final encounter rate (ER) and group size (GS) generalized additive models (built using the S-PLUS gam algorithm). L1: linear fits; S\#: smoothing splines, where \# is the associated degrees of freedom. Potential predictor variables were: distance to the $2000 \mathrm{~m}$ isobath (D2000), depth, slope, sea-surface temperature (SST), the coefficient of variation (CV) of SST, Beaufort sea state (BF), mixed-layer depth (MLD), the natural log of chlorophyll (CHL), and sea-surface salinity (SSS). (-) Predictor variable did not enter the final model

\begin{tabular}{|c|c|c|c|c|c|c|c|c|c|c|c|c|}
\hline \multirow{2}{*}{ Species } & \multirow{2}{*}{ Model } & \multirow{2}{*}{$\begin{array}{l}\text { Exp. } \\
\text { dev. }\end{array}$} & \multirow{2}{*}{ ASPE } & \multirow[b]{2}{*}{ D2000 } & \multirow[b]{2}{*}{ Depth } & \multirow[b]{2}{*}{ Slope } & \multicolumn{3}{|c|}{ Predictor variables } & \multirow[b]{2}{*}{$\mathrm{MLD}^{\mathrm{b}}$} & \multirow[b]{2}{*}{$\mathrm{CHL}^{\mathrm{b}}$} & \multirow[b]{2}{*}{$\mathrm{SSS}^{\mathrm{b}}$} \\
\hline & & & & & & & $\mathrm{SST}^{\mathrm{a}}$ & $\mathrm{CV}(\mathrm{SST})^{\mathrm{a}}$ & $\mathrm{BF}$ & & & \\
\hline Striped dolphin & ER & 0.10 & 0.04 & - & $\mathrm{S} 2$ & - & $\mathrm{S} 2$ & - & L1 & - & - & - \\
\hline Stenella coeruleoalba & GS & 0.09 & 4429 & - & - & - & L1 & - & - & - & - & - \\
\hline Short-beaked common dolphin & ER & 0.13 & 0.17 & - & S3 & - & S3 & $\mathrm{S} 2$ & L1 & S3 & S3 & S3 \\
\hline Delphinus delphis & GS & 0.02 & 61267 & - & - & - & L1 & - & L1 & - & - & - \\
\hline Risso's dolphin & ER & 0.08 & 0.07 & CAT $^{\mathrm{c}}$ & - & - & - & - & $\mathrm{S} 2$ & - & - & - \\
\hline Grampus griseus & GS & 0.05 & 743.71 & - & - & L1 & - & - & - & - & - & - \\
\hline Pacific white-sided dolphin & ER & 0.28 & 0.12 & - & S3 & - & S3 & - & S3 & S3 & L1 & - \\
\hline Lagenorhynchus obliquidens & GS & 0.35 & 44405 & - & $\mathrm{S} 2$ & - & - & - & L1 & - & - & L1 \\
\hline Northern right whale dolphin & ER & 0.18 & 0.04 & - & S3 & - & S3 & - & S3 & L1 & L1 & $\mathrm{S} 2$ \\
\hline Lissodelphis borealis & GS & 0.17 & 12423 & - & - & & - & - & L1 & L1 & - & - \\
\hline Dall's porpoise & ER & 0.42 & 0.37 & - & S3 & L1 & S3 & - & S3 & S3 & S3 & S3 \\
\hline Phocoenoides dalli & GS & 0.11 & 8.20 & - & - & S3 & $\mathrm{S} 2$ & - & - & L1 & $\mathrm{S} 2$ & \\
\hline Sperm whale & ER & 0.05 & 0.09 & - & $\mathrm{S} 2$ & - & - & S3 & $\mathrm{S} 2$ & - & S3 & - \\
\hline Physeter macrocephalus & GS & 0.05 & 61.95 & L1 & - & - & L1 & - & - & - & - & - \\
\hline Fin whale & ER & 0.09 & 0.09 & - & S3 & - & S3 & L1 & L1 & - & - & - \\
\hline Balaenoptera physalus & GS & 0.06 & 1.86 & S3 & - & - & - & S3 & - & - & - & - \\
\hline Blue whale & ER & 0.22 & 0.14 & - & S3 & S3 & S3 & - & S3 & S3 & $\mathrm{S} 3$ & S3 \\
\hline Balaenoptera musculus & GS & 0.08 & 0.75 & - & - & L1 & L1 & - & - & L1 & - & - \\
\hline Humpback whale & ER & 0.33 & 0.10 & L1 & L1 & $\mathrm{S} 2$ & S3 & L1 & L1 & - & - & - \\
\hline Megaptera novaeangliae & GS & 0 & 2.25 & - & - & - & - & - & - & - & - & - \\
\hline Baird's beaked whale & ER & 0.08 & 0.02 & $\mathrm{CAT}^{\mathrm{d}}$ & - & - & - & - & - & - & - & - \\
\hline Berardius bairdii & GS & 0.35 & 26.79 & $\mathrm{CAT}^{\mathrm{d}}$ & - & - & - & - & - & - & - & - \\
\hline Small beaked whales & ER & 0.07 & 0.08 & - & L1 & L1 & - & - & L1 & - & - & - \\
\hline $\begin{array}{l}\text { Ziphius cavirostris and } \\
\text { Mesoplodon spp. }\end{array}$ & GS & 0.14 & 1.08 & - & - & - & - & L1 & $\mathrm{S} 2$ & - & - & - \\
\hline
\end{tabular}


Table 4. Average abundances (numbers of individuals, N) predicted based on results from the final California Current Ecosystem models and derived from the standard line-transect estimates for 1991, 1993, 1996, and 2001 that were based on the same values of $f(0)$ and $g(0)$ used by Barlow (2003). In all cases, model estimates are within the $95 \%$ confidence limits (CI) of the average calculated from Barlow's (2003) values. Taxonomic names as in Table 3

\begin{tabular}{|lccc|}
\hline \multirow{2}{*}{$\begin{array}{c}\text { Species } \\
\text { Model }\end{array}$} & $\begin{array}{c}\text { Average } \\
\text { Barlow (2003) }\end{array}$ \\
& $\mathrm{N}$ & $\mathrm{N}$ & $95 \% \mathrm{CI}$ \\
\hline $\begin{array}{l}\text { Striped dolphin } \\
\text { Short-beaked }\end{array}$ & 22146 & 18766 & $10459 / 33670$ \\
$\quad$ Common dolphin & 507660 & 449881 & $314357 / 643832$ \\
Risso's dolphin & 19797 & 16603 & $10441 / 26402$ \\
Pacific white-sided & 33154 & 46286 & $20514 / 104435$ \\
$\quad$ dolphin & & & \\
Northern right & 16890 & 19420 & $12630 / 29861$ \\
$\quad$ whale dolphin & & & \\
Dall's porpoise & 66467 & 90391 & $50041 / 163277$ \\
Sperm whale & 1234 & 1293 & $726 / 2301$ \\
Fin whale & 3388 & 2842 & $1749 / 4618$ \\
Blue whale & 2862 & 2079 & $1503 / 2875$ \\
Humpback whale & 1373 & 1123 & $699 / 1803$ \\
Baird's beaked whale & 600 & 437 & $203 / 940$ \\
Small beaked whales & 8259 & 6240 & $3354 / 11608$ \\
\hline
\end{tabular}

\section{Spatial density models: CCE}

Final best models for the 11 cetacean species and 1 species guild in the CCE included a mixture of models based on remotely sensed predictor variables (i.e. they did not include any in situ variables), and models that included a combination of remotely sensed and in situ variables in addition to the static bathymetric variables (Table 3). Variables that were included in many of the species' final encounter rate models were SST, depth, and sea state, the latter reflecting this variable's effect on detection probability. MLD, CV(SST), CHL, and SSS were included for fewer species. The percentage of deviance explained ranged from $5 \%$ (sperm whale) to $42 \%$ (Dall's porpoise) for encounter rate models and from $0 \%$ (humpback whale) to $35 \%$ (Pacific white-sided dolphin) for group size models. Model validation using the novel 2005 dataset revealed that the initial models for Risso's dolphin and Baird's beaked whale were not effective at capturing their distribution patterns, and models for both species yielded better results using categorical static variables representing regional or slope categories. Except for these 2 categorical variables, functional forms between predictor and response ranged from linear ('L1' in Table 3) to smoothing spline functions with 3 df (S3).
Density plots comparing observed sighting locations to a sample of yearly predictions ( 3 of the total 5) and the multi-year average, with $90 \%$ confidence limits (Figs. 2 to 4), showed that the final CCE models were broadly effective at capturing general distribution patterns of the 12 modeled cetacean species and guild. Across all years, density ratios for all models ranged from 0.86 to 1.50 , indicating that average model-based density estimates were similar to comparable line-transect density estimates calculated from the same segments. Study-area wide model-based abundance estimates were also similar to previous line-transect estimates that used the same $f(0)$ and $g(0)$ values (Barlow 2003; Table 4). Uncertainty in the model predictions was generally greater off Oregon and Washington, where fewer surveys were conducted (in 1991 and 1993, surveys were only conducted off California). Variance was also greater for species with a large range in group size, e.g. short-beaked common dolphins, and smaller for large whale species and Dall's porpoises, which occur in smaller groups.

\section{Spatial density models: ETP}

The final best models for ETP cetaceans were based on static and in situ habitat data and included smoothing splines with df ranging from 0 to about 9 , plus 1 interaction term requiring $19.5 \mathrm{df}$ (Table 5). Based on the comparison of simple and complex encounter rate and group size models, the simple models were chosen as the final best models for all taxa except Cuvier's beaked whale. Encounter rate models for common bottlenose dolphins, Cuvier's beaked whales, whitebelly spinner dolphins, and blue whales failed to converge with the default settings in the mgcr gam algorithm, but the convergence was achieved by setting the irls.reg parameter in the gam.control argument in these models to a value of 1.0 (see $\mathrm{R}$ helpfile for gam.control in $\mathrm{mgcv}$ for details on the use of the irls.reg parameter).

Predicted distributions of population density for the 14 ETP taxonomic categories revealed interannual variability in distribution for most species (Figs. 5 to 9). Density predictions for Mesoplodon spp. (Fig. 9) show 2 general areas of high density: the waters of the equatorial cold tongue that straddles the equator, and the coastal waters off central America and Mexico. These areas correspond to known patterns of distribution for Blainville's beaked whale $M$. densirostris and the Peruvian beaked whale $M$. peruvianus, respectively (Pitman \& Lynn 2001). Thus, 

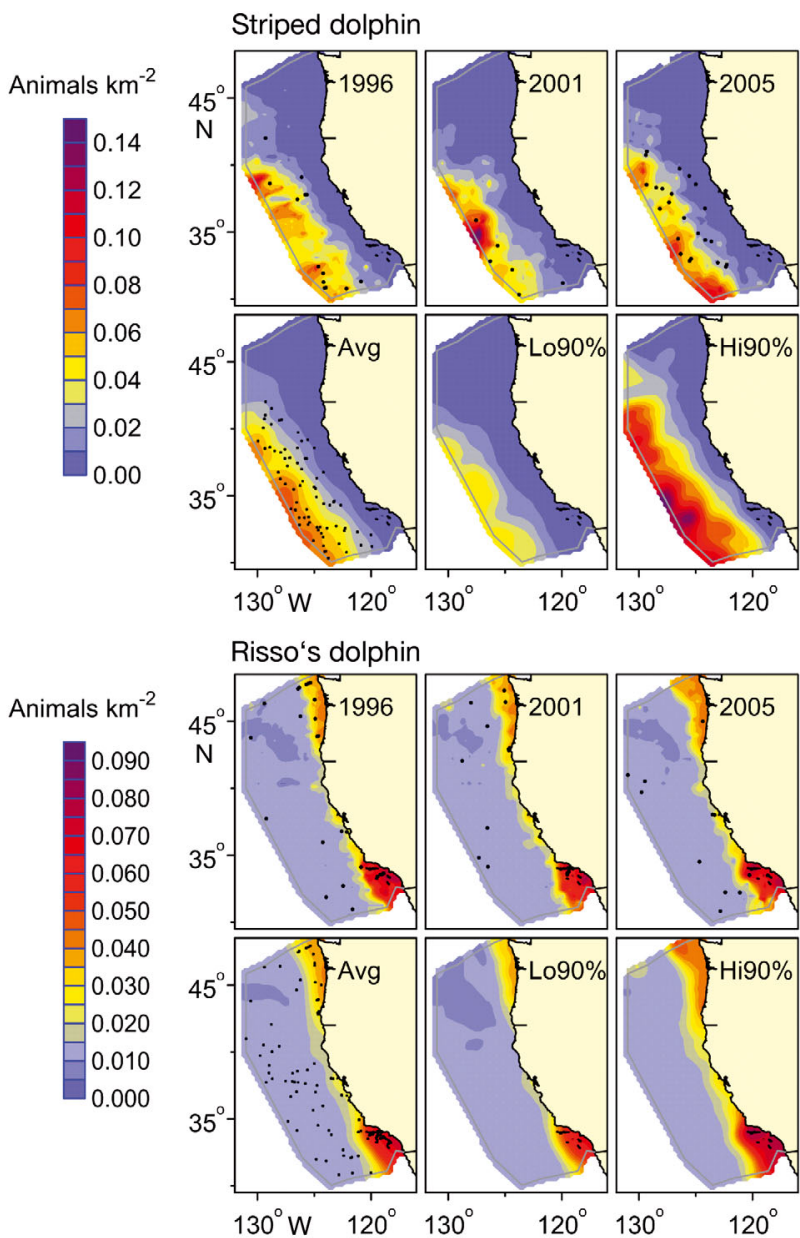
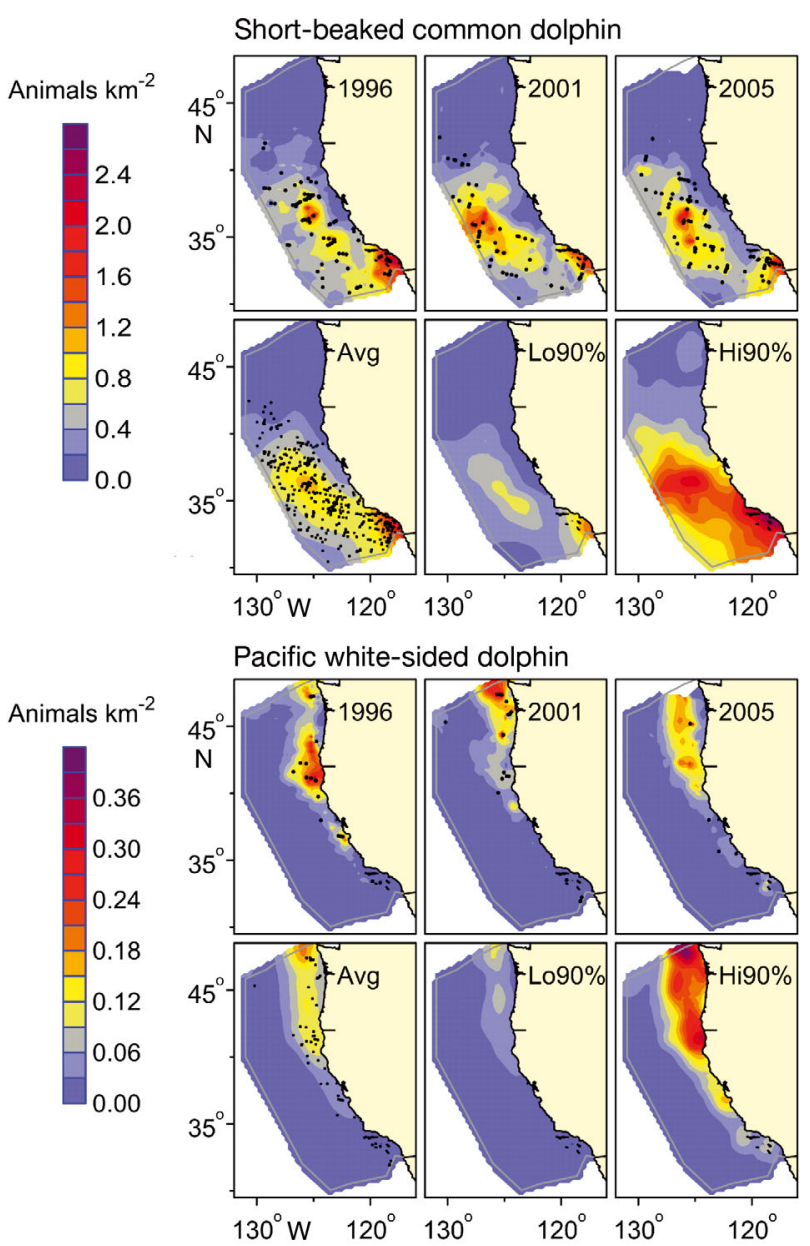

Fig. 2. Modeled species densities for striped dolphin, short-beaked common dolphin, Risso's dolphin, and Pacific white-sided dolphin in the California Current Ecosystem. Panels show 3 sample years $(1996,2001,2005)$, the multi-year average, and $90 \%$ confidence limits. Dots are observed sighting locations for each time period. Taxonomic names as in Table 3

although sample sizes were insufficient to build separate models for each species of Mesoplodon, the genus-level model was able to identify the known patterns of distribution for the 2 dominant Mesoplodon species in the ETP. The plots for Bryde's whales (Fig. 8) highlight the need to consider survey effort along with the distribution of sightings when interpreting the density plots. Although the Bryde's whale sightings appear to be relatively uniform throughout the study area, there is considerably less survey effort in the southern region, which translates to higher overall densities in these waters. As with the CCE models, estimates of uncertainty for all species were greatest in areas where survey effort was least (for example, around the margins of the study areas) and for species having the greatest range in encounter rate and group size (for example, spotted, striped, eastern spinner, and whitebelly spinner dolphins). Eastern and whitebelly spinner dolphins were successfully separated geographically (Fig. 5) using the tensor product spline with latitude, longitude, and SST. Lastly, we attempted to build encounter rate and group size models for sperm whales, killer whales, and coastal spotted dolphins, but the models for these 3 species failed to converge or produced predictions that were determined by the expert review panel to be inconsistent with known occurrence patterns.

\section{DISCUSSION}

\section{Methodological choices}

In the present study, we evaluated different aspects of the model development that were relevant to each study area, and used the ETP data to examine the effects of algorithm selection on model results. 

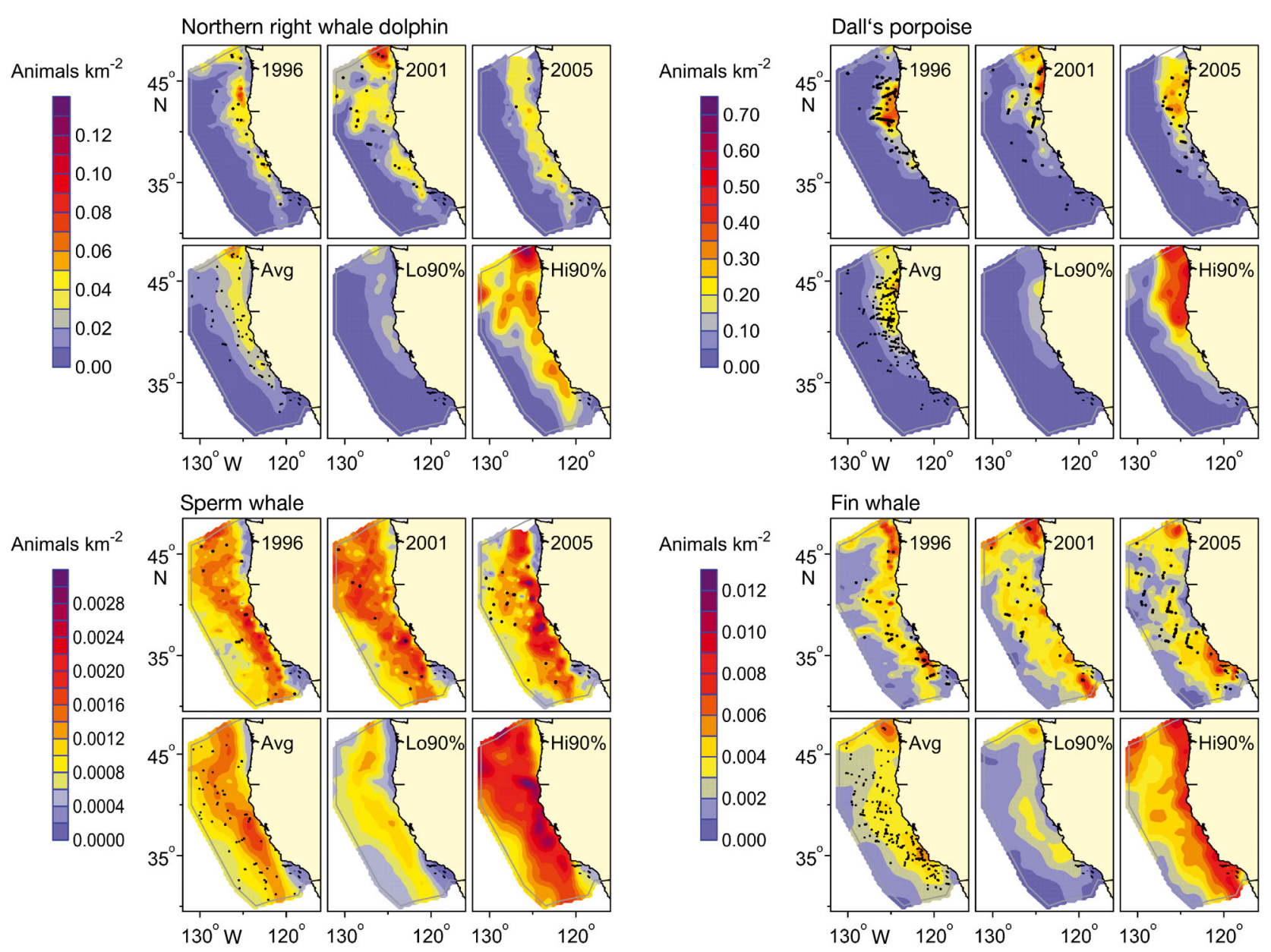

Fig. 3. Modeled species densities for northern right whale dolphin, Dall's porpoise, sperm whale, and fin whale in the California Current Ecosystem. Panels show 3 sample years (1996, 2001, 2005), the multi-year average, and $90 \%$ confidence limits. Dots are observed sighting locations for each time period. Taxonomic names as in Table 3

The comparison of interpolation methods showed that there is not a single 'best' method for interpolating the oceanographic observations, and we chose ordinary kriging because this method was least susceptible to bull's eyes, edge effects, or other artifacts where data were sparse. The kriged yearly fields produced for cetacean-habitat modeling captured both mesoscale and larger scale habitat variability that might influence the distribution of cetaceans. However, it is important to remember that the yearly field was neither a snapshot nor a mean of the dynamic oceanographic conditions during the 3 to 4 mo survey. Rather, it represents a synoptic measure of summer/fall conditions for each survey year, based on the oceanographic data collected concurrently with the cetacean sighting data. Preliminary models that investigated alternate methods of including oceanographic data (e.g. using only along-track or daily station data) had lower explanatory and predic- tive power, likely because such approaches resulted in greater data loss and/or coarser resolution of the oceanographic data. While the use of an interpolated field does not allow consideration of within-survey temporal variability, it was nonetheless able to capture species-habitat patterns adequately for our models. However, for future prediction it might be better to use fields of oceanographic parameters derived from ocean-atmosphere models that assimilate ship, buoy, and remotely sensed data (e.g. Carton et al. 2000).

The choice of modeling algorithm did not dramatically affect the resulting models, but 2 features of the mgcv gam algorithm distinguished it from the S-PLUS counterpart and made it the preferred algorithm in the ETP. First, the predict.gam function in mgcv did not require the original dataset to make predictions from a parameterized GAM. This was in contrast to the S-PLUS predict.gam algorithm, which 

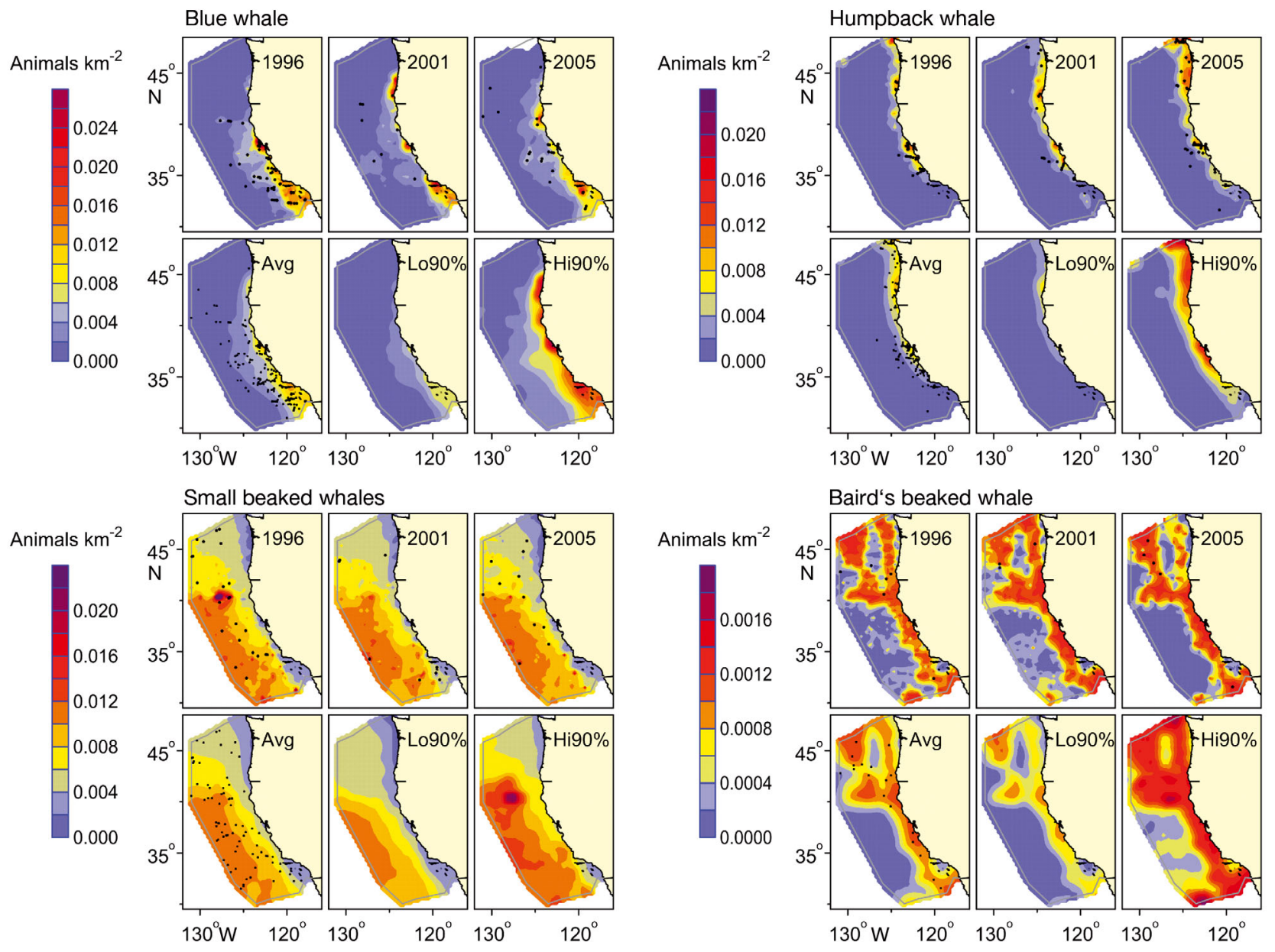

Fig. 4. Modeled species densities for blue whale, humpback whale, small beaked whales, and Baird's beaked whale in the California Current Ecosystem. Panels show 3 sample years (1996, 2001, 2005), the multi-year average, and $90 \%$ confidence limits. Dots are observed sighting locations for each time period. Taxonomic names as in Table 3

produced a run-time error and stopped working if the original dataset was not in the working directory. The practical consequence of this restriction is that a model developer working in the S-PLUS environment must provide both the original data and the gam model object to anyone interested in making predictions from the model. The second desirable feature of mgcv gam is its ability to construct a variety of multidimensional smooth terms. Incorporating tensor product smooths improved the predictive performance of the ETP eastern spinner dolphin and Cuvier's beaked whale encounter rate models.

Based on the model comparison, we believe it is worthwhile to compare models built using a variety of tools. Choice of the 'preferred' tool is likely to be case-specific, but it is best to be fully aware of the advantages and disadvantages of alternative modeling methods and algorithms. Further, model evaluation should encompass a suite of model evaluation techniques. It was rare that all model evaluation techniques in our study pointed to the same 'best' model, because they were evaluating difference aspects of model performance. Quantitative statistics, such as explained deviance or the overall observed-to-predicted ratios, provide broad measures of average model performance but do not explicitly consider spatial accuracy. ASPE and visual inspection of density maps allow spatial assessment of model performance, but it is difficult to quantify concordance between observations and predictions or between plots derived from different models.

The output from an ecological model is an approximation to truth (Burnham \& Anderson 1998), and there are numerous sources of uncertainty in the cetacean-habitat population density models, including uncertainty arising from survey design, stochasticity inherent in the sighting process, measurement error, model parameter estimation errors, and model selec- 
Table 5. Effective degrees of freedom for each predictor variable included in the final eastern tropical Pacific models (SST: sea-surface temperature; SSS: sea-surface salinity; MLD: mixed-layer depth; CHL: natural log of chlorophyll; BF: Beaufort sea state). Terms with effective degrees of freedom (df) $<1 \times 10^{-4}$ are represented as 0.00. Taxonomic names as in Table 1. (-) Predictor variable did not enter the final model

\begin{tabular}{|c|c|c|c|c|c|c|c|c|}
\hline Species & Model & $\begin{array}{l}\text { Offshore } \\
\text { distance }\end{array}$ & Depth & SST & SSS & MLD & CHL & $\mathrm{BF}$ \\
\hline $\begin{array}{l}\text { Pantropical } \\
\text { spotted dolphin }\end{array}$ & $\begin{array}{l}\text { ER } \\
\text { GS }\end{array}$ & $\begin{array}{l}0.00 \\
1.89\end{array}$ & $\begin{array}{l}2.37 \\
0.35\end{array}$ & $\begin{array}{l}1.76 \\
0.00\end{array}$ & $\begin{array}{l}1.79 \\
0.00\end{array}$ & $\begin{array}{l}1.00 \\
1.35\end{array}$ & $\begin{array}{l}0.00 \\
0.24\end{array}$ & $\begin{array}{l}- \\
-\end{array}$ \\
\hline $\begin{array}{l}\text { Eastern } \\
\text { spinner dolphin }\end{array}$ & $\begin{array}{l}\mathrm{ER}^{\mathrm{a}} \\
\mathrm{GS}\end{array}$ & $\begin{array}{l}2.01 \\
4.11\end{array}$ & $\begin{array}{l}2.71 \\
2.07\end{array}$ & $\begin{array}{l}1.00 \\
2.19\end{array}$ & $\begin{array}{l}0.57 \\
2.28\end{array}$ & $\begin{array}{l}2.28 \\
1.72\end{array}$ & $\begin{array}{l}0.54 \\
0.00\end{array}$ & $\begin{array}{l}3.63 \\
0.87\end{array}$ \\
\hline $\begin{array}{l}\text { Whitebelly } \\
\text { spinner dolphin }\end{array}$ & $\begin{array}{l}\text { ER } \\
\text { GS }\end{array}$ & $\begin{array}{l}3.00 \\
0.00\end{array}$ & $\begin{array}{l}3.27 \\
0.98\end{array}$ & $\begin{array}{l}2.56 \\
0.81\end{array}$ & $\begin{array}{l}7.79 \\
0.00\end{array}$ & $\begin{array}{l}3.81 \\
0.00\end{array}$ & $\begin{array}{l}1.09 \\
0.00\end{array}$ & $\begin{array}{l}1.11 \\
0.00\end{array}$ \\
\hline Striped dolphin & $\begin{array}{l}\text { ER } \\
\text { GS }\end{array}$ & $\begin{array}{l}6.94 \\
0.83\end{array}$ & $\begin{array}{l}4.30 \\
1.22\end{array}$ & $\begin{array}{l}4.36 \\
0.97\end{array}$ & $\begin{array}{l}0.00 \\
5.63\end{array}$ & $\begin{array}{l}1.94 \\
3.86\end{array}$ & $\begin{array}{l}2.12 \\
0.12\end{array}$ & $\begin{array}{l}2.86 \\
0.01\end{array}$ \\
\hline $\begin{array}{l}\text { Rough-toothed } \\
\text { dolphin }\end{array}$ & $\begin{array}{l}\text { ER } \\
\text { GS }\end{array}$ & 000 & $\begin{array}{l}2.23 \\
0.00\end{array}$ & $\begin{array}{l}4.48 \\
1.14\end{array}$ & $\begin{array}{l}0.00 \\
0.67\end{array}$ & $\begin{array}{l}0.00 \\
0.00\end{array}$ & $\begin{array}{l}0.48 \\
1.33\end{array}$ & $\begin{array}{l}1.72 \\
0.58\end{array}$ \\
\hline $\begin{array}{l}\text { Short-beaked } \\
\text { common dolphin }\end{array}$ & $\begin{array}{l}\text { ER } \\
\text { GS }\end{array}$ & $\begin{array}{l}2.33 \\
0.00\end{array}$ & $\begin{array}{l}6.37 \\
0.01\end{array}$ & $\begin{array}{l}2.11 \\
0.48\end{array}$ & $\begin{array}{l}0.83 \\
0.78\end{array}$ & $\begin{array}{l}1.39 \\
6.86\end{array}$ & $\begin{array}{l}2.69 \\
1.15\end{array}$ & $\begin{array}{l}1.02 \\
1.68\end{array}$ \\
\hline $\begin{array}{l}\text { Common } \\
\text { bottlenose dolphin }\end{array}$ & $\begin{array}{r}\text { ER } \\
\text { GS }\end{array}$ & & & $\begin{array}{l}1.44 \\
0.88\end{array}$ & $\begin{array}{l}5.34 \\
1.63\end{array}$ & $\begin{array}{l}0.90 \\
0.00\end{array}$ & $\begin{array}{l}1.86 \\
0.00\end{array}$ & $\begin{array}{l}0.88 \\
2.98\end{array}$ \\
\hline Risso's dolphin & $\begin{array}{l}\text { ER } \\
\text { GS }\end{array}$ & $\begin{array}{l}2.09 \\
1.94\end{array}$ & $\begin{array}{l}3.25 \\
0.00\end{array}$ & $\begin{array}{l}2.83 \\
1.46\end{array}$ & $\begin{array}{l}2.98 \\
0.00\end{array}$ & $\begin{array}{l}0.00 \\
0.75\end{array}$ & $\begin{array}{l}1.79 \\
0.00\end{array}$ & $\begin{array}{l}1.31 \\
0.88\end{array}$ \\
\hline $\begin{array}{l}\text { Cuvier's } \\
\text { beaked whale }\end{array}$ & $\begin{array}{l}\text { ER } \\
\text { GS }\end{array}$ & $\begin{array}{l}1.17 \\
2.97\end{array}$ & $\begin{array}{l}2.31 \\
2.21\end{array}$ & $\begin{array}{l}2.47 \\
2.06\end{array}$ & $\begin{array}{l}0.00 \\
1.54\end{array}$ & $\begin{array}{l}0.00 \\
2.41\end{array}$ & $\begin{array}{l}2.06 \\
2.84\end{array}$ & $\begin{array}{l}0.97 \\
2.60\end{array}$ \\
\hline Blue whale & $\begin{array}{l}\text { ER } \\
\text { GS }\end{array}$ & $\begin{array}{l}3.60 \\
1.22\end{array}$ & $\begin{array}{l}4.91 \\
0.81\end{array}$ & $\begin{array}{l}5.59 \\
0.53\end{array}$ & $\begin{array}{l}3.42 \\
0.00\end{array}$ & $\begin{array}{l}3.56 \\
2.59\end{array}$ & $\begin{array}{l}3.14 \\
2.42\end{array}$ & $\begin{array}{l}0.00 \\
0.00\end{array}$ \\
\hline Bryde's whale & $\begin{array}{l}\text { ER } \\
\text { GS }\end{array}$ & $\begin{array}{l}0.04 \\
2.44\end{array}$ & $\begin{array}{l}2.54 \\
3.76\end{array}$ & $\begin{array}{l}2.36 \\
0.00\end{array}$ & $\begin{array}{l}0.96 \\
0.00\end{array}$ & $\begin{array}{l}0.87 \\
0.00\end{array}$ & $\begin{array}{l}2.85 \\
0.00\end{array}$ & $\begin{array}{l}0.67 \\
0.00\end{array}$ \\
\hline $\begin{array}{l}\text { Short-finned } \\
\text { pilot whale }\end{array}$ & $\begin{array}{l}\text { ER } \\
\text { GS }\end{array}$ & $\begin{array}{l}1.16 \\
2.21\end{array}$ & $\begin{array}{l}5.87 \\
0.00\end{array}$ & $\begin{array}{l}1.81 \\
0.88\end{array}$ & $\begin{array}{l}3.73 \\
0.00\end{array}$ & $\begin{array}{l}0.00 \\
1.50\end{array}$ & $\begin{array}{l}1.38 \\
0.00\end{array}$ & $\begin{array}{l}2.23 \\
0.85\end{array}$ \\
\hline Dwarf sperm whale & $\begin{array}{l}\text { ER } \\
\text { GS }\end{array}$ & $\begin{array}{l}0.00 \\
1.06\end{array}$ & $\begin{array}{l}0.00 \\
0.79\end{array}$ & $\begin{array}{l}8.97 \\
0.00\end{array}$ & $\begin{array}{l}0.00 \\
0.00\end{array}$ & $\begin{array}{l}0.00 \\
0.00\end{array}$ & $\begin{array}{l}8.97 \\
0.00\end{array}$ & $\begin{array}{l}8.98 \\
0.00\end{array}$ \\
\hline Mesoplodon spp. & $\begin{array}{l}\text { ER } \\
\text { GS }\end{array}$ & $\begin{array}{l}8.92 \\
1.38\end{array}$ & $\begin{array}{l}8.95 \\
0.45\end{array}$ & $\begin{array}{l}8.97 \\
1.90\end{array}$ & $\begin{array}{l}8.74 \\
3.22\end{array}$ & $\begin{array}{l}0.00 \\
0.00\end{array}$ & $\begin{array}{l}8.95 \\
0.00\end{array}$ & $\begin{array}{l}7.77 \\
2.47\end{array}$ \\
\hline
\end{tabular}

tion error. To complicate matters, these sources of uncertainty and the data themselves are not independent, making the development of analytical methods for estimating variance intractable. Given the large range in the magnitude of uncertainty introduced by each of these sources, it is not always necessary to quantify the uncertainty associated with each source to derive a relatively accurate estimate of overall uncertainty. Rather, estimation of the uncertainty contributed by the dominant sources is often sufficient. In our analyses, the greatest source of uncertainty was determined to be the interannual variability in population density due to movement of animals within or outside of the study areas, and we focused on this source of uncertainty to produce approximate estimates of variance for the spatial density estimates.

\section{Spatial cetacean density models}

The current study represents the most comprehensive spatial density modeling effort for cetaceans to date, covering 22 species within a broad region of the temperate and tropical eastern Pacific Ocean and including more years of survey effort than any previous modeling study. Several new lines of research on model methodology have been presented in this study and in related, previously published studies (Becker 2007, Redfern et al. 2008, Becker et al. 2010), including evaluations of algorithm choice, interpolation methods, model crossvalidation, effects of scale, use of remotely sensed versus in situ habitat data, and seasonal predictive capabilities. Our research has confirmed that GAMs offer a robust framework for predictive cetacean density models, as long as sufficient observations of each species are available and the surveys adequately characterize the full range of oceanographic variability.

Within the CCE and ETP, the multiyear average maps provide the first spatially explicit estimates of summer/fall cetacean density and variance therein. The successful conservation and management of cetaceans requires that potential anthropogenic impacts are correctly assessed, and the models developed in the present study represent a new tool to improve accuracy and allow estimation of spatial and temporal heterogeneity of cetacean densities within specific areas of interest, such as naval operations areas. For example, there is considerable inshore-offshore variation in the densities of cetaceans off Southern California (Figs. 2 to 4), but previous summer/fall line-transect estimates (Barlow \& Forney 2007) provided only an average, uniform density from the coast out to 300 nautical miles offshore. For all species that are more abundant in shelf/slope waters (including endangered blue, fin, and humpback whales), potential impacts nearshore would thus have been underestimated, while those offshore would have been overestimated. The new models allow more accurate estimation of regional densities, and provide confidence limits based on observed 


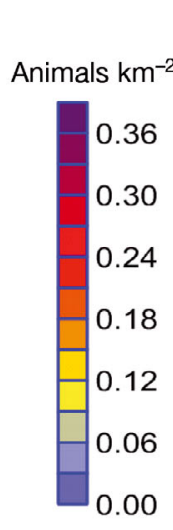

Pantropical spotted dolphin
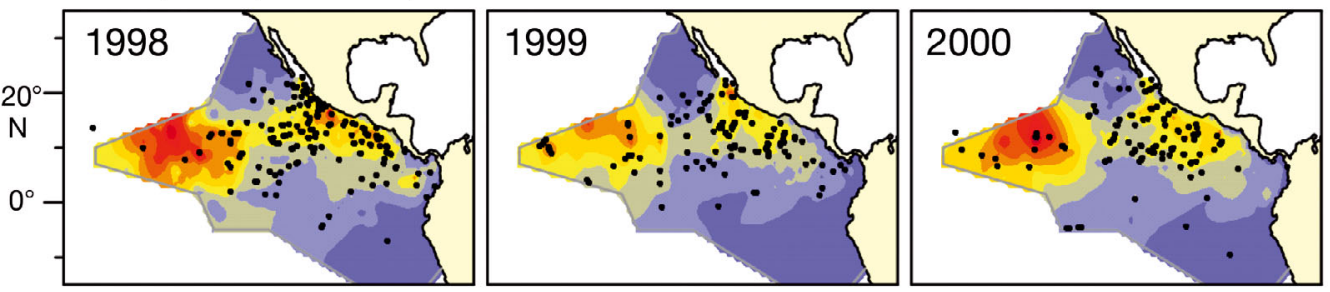

0.18
0.12
0.06
0.00
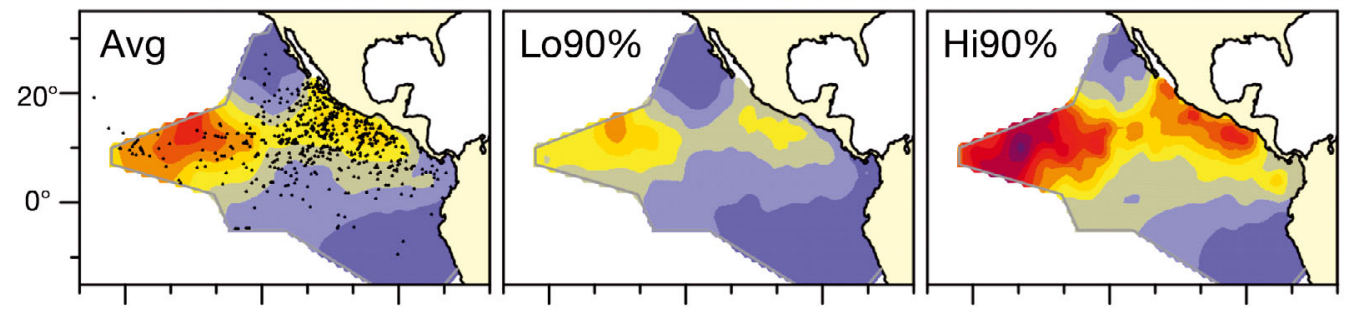

Whitebelly spinner dolphin
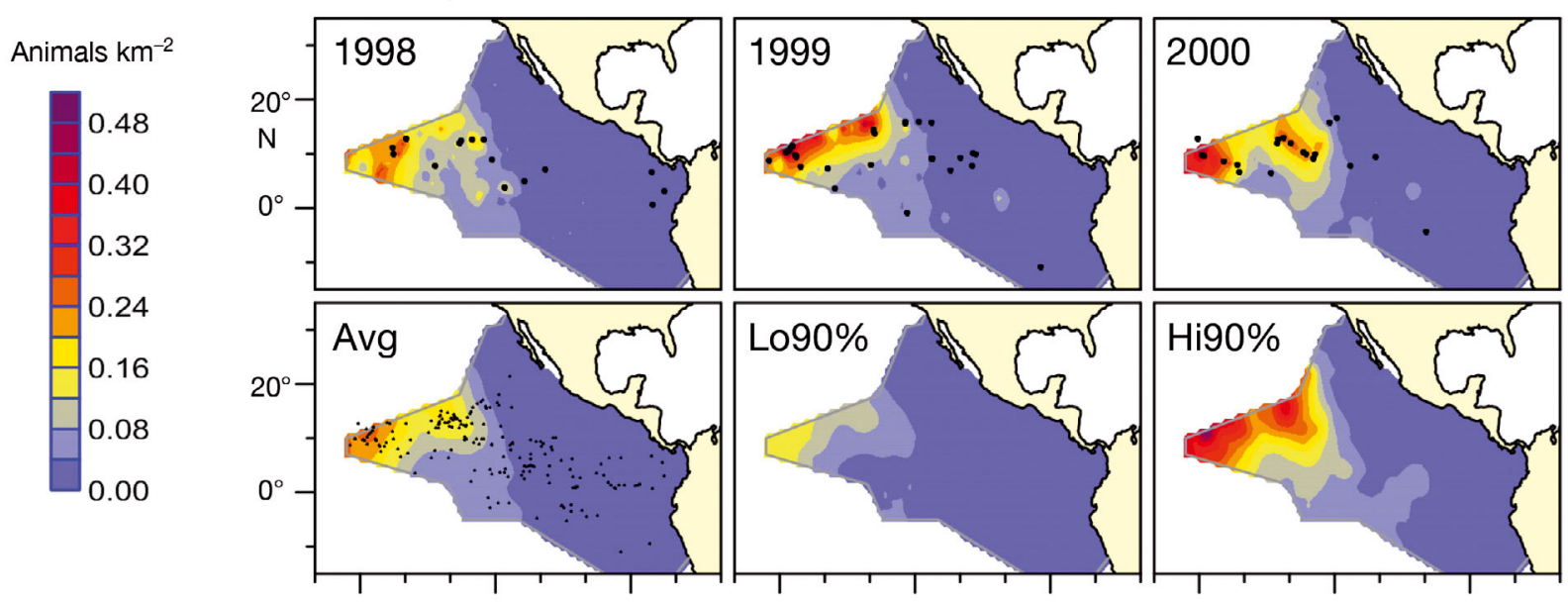

Eastern spinner dolphin
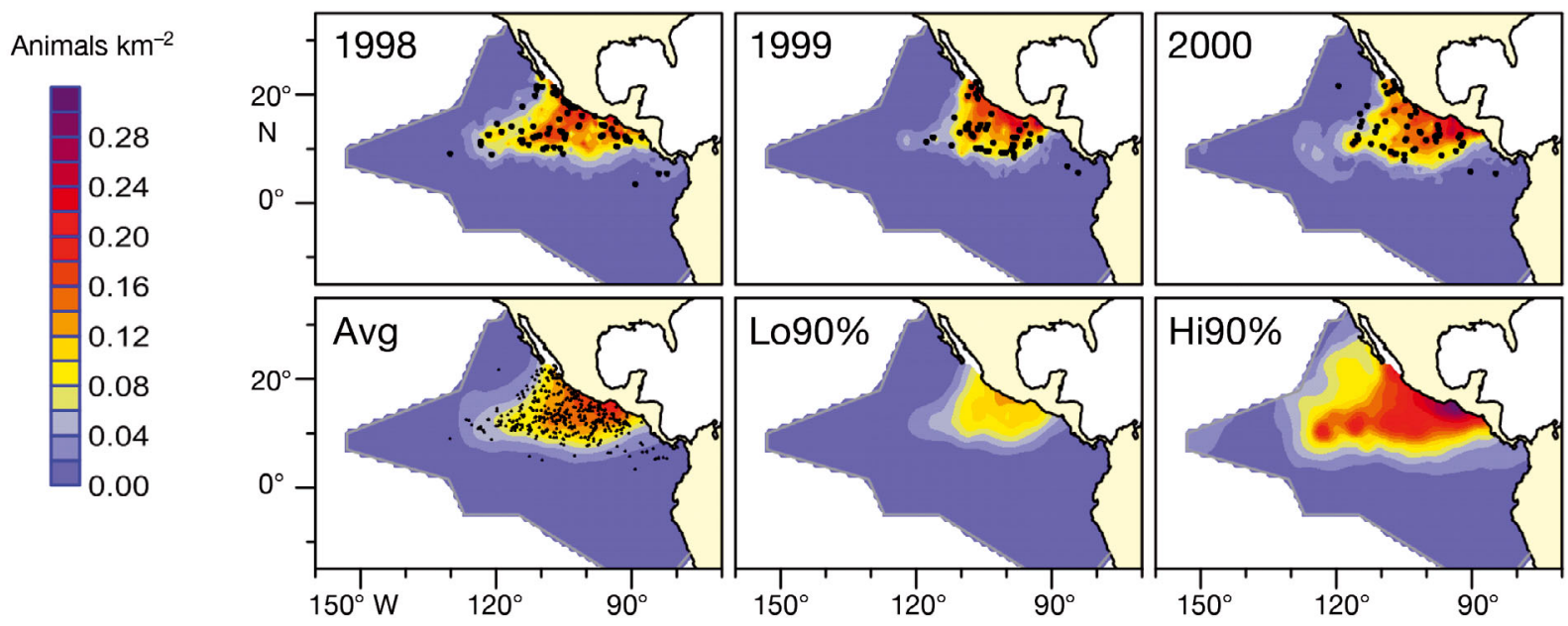

Fig. 5. Modeled species densities for pantropical spotted dolphin, whitebelly spinner dolphin, and eastern spinner dolphin in the eastern tropical Pacific. Panels show 3 sample years (1998 [end of a major El Niño], 1999 [La Niña], and 2000 [ENSOneutral]), the multi-year average, and $90 \%$ confidence limits. Dots are observed sighting locations for each time period. Taxo- 

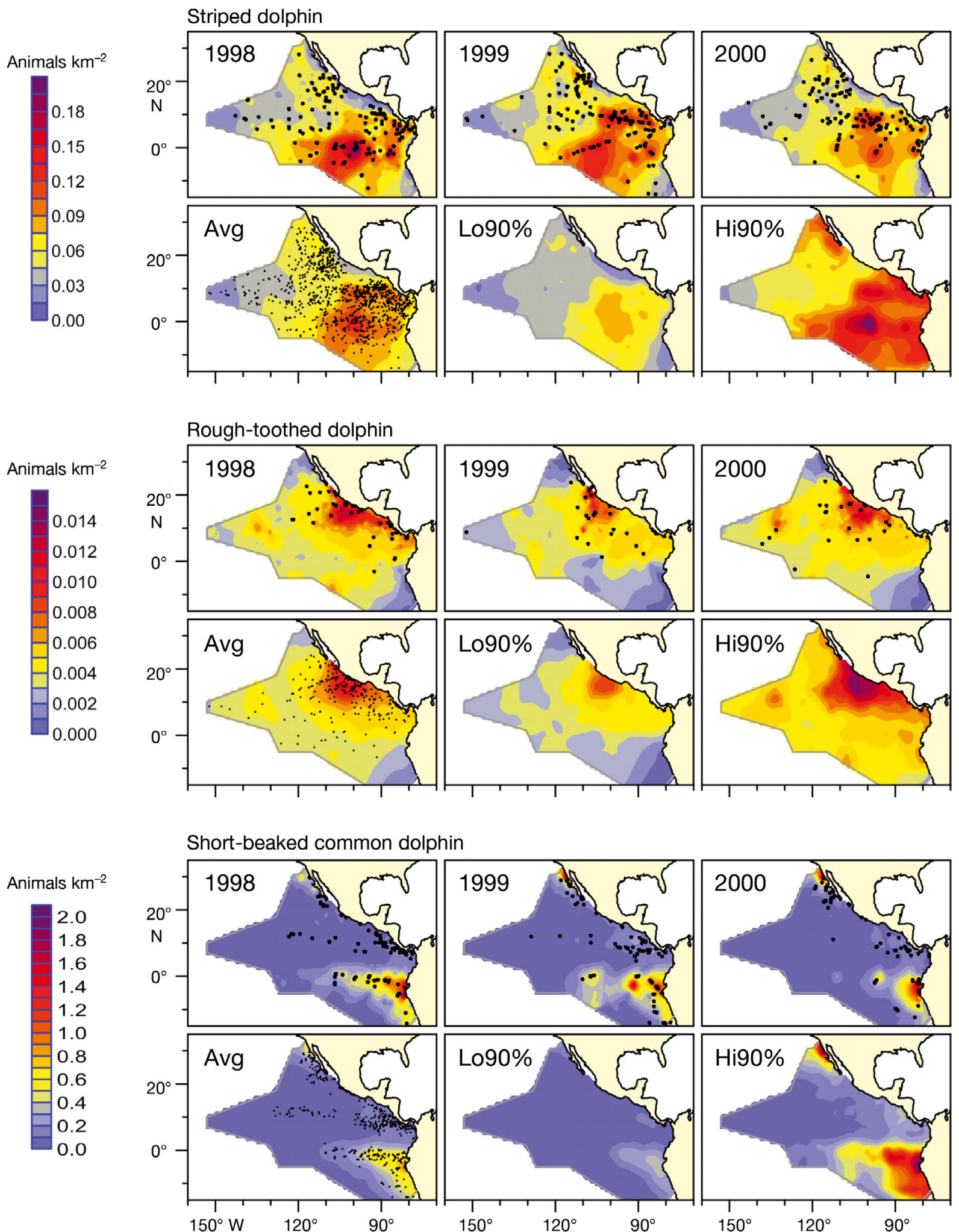

Fig. 6. Modeled species densities for striped dolphin, rough-toothed dolphin, and short-beaked common dolphin in the eastern tropical Pacific. Panels show 3 sample years (1998 [end of a major El Niño], 1999 [La Niña], and 2000 [ENSO-neutral]), the multi-year average, and $90 \%$ confidence limits. Dots are observed sighting locations for each time period. Taxonomic names as in Table 1 


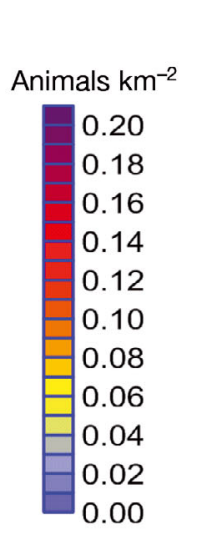

\section{Bottlenose dolphin}
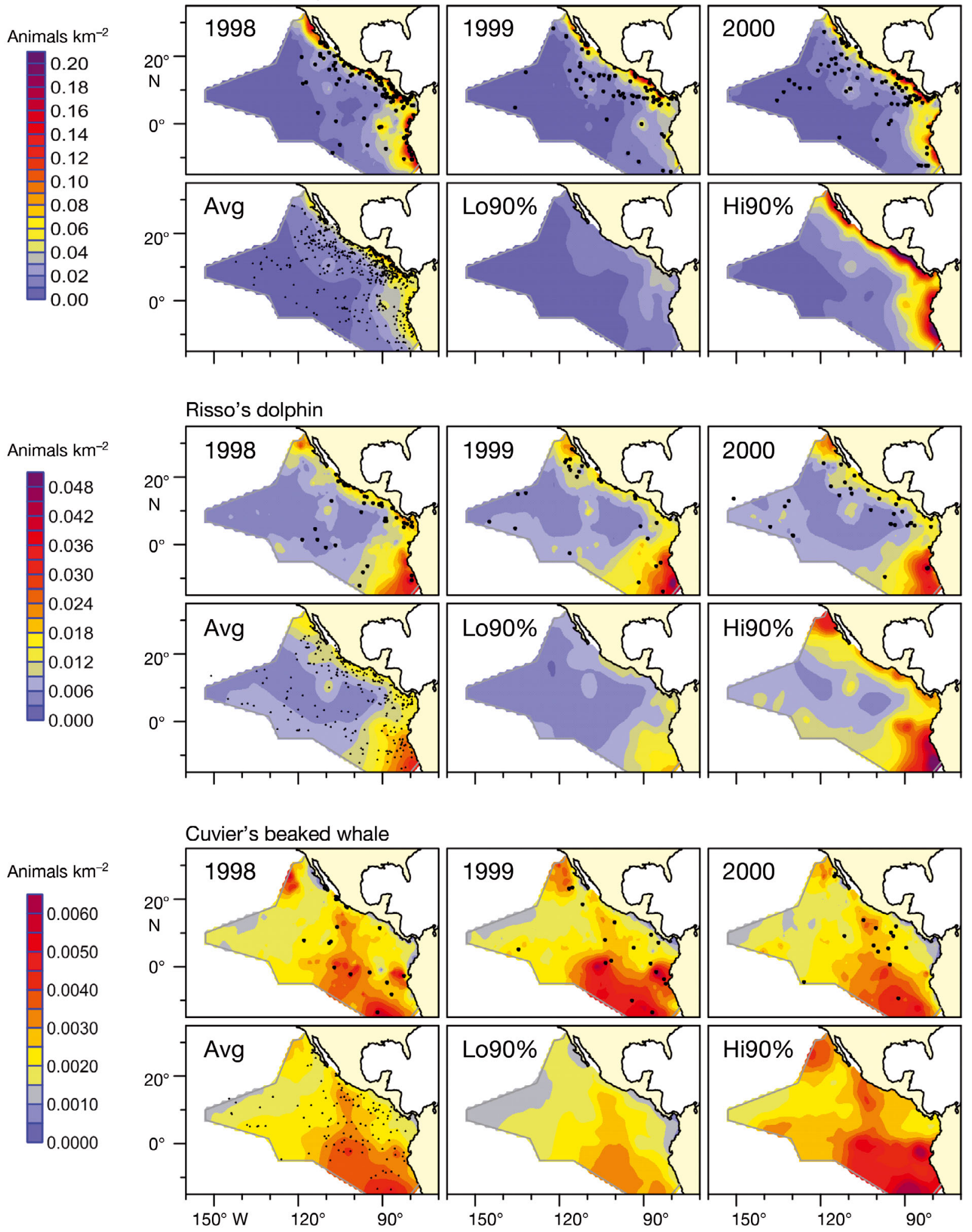

Fig. 7. Modeled species densities for common bottlenose dolphin, Risso's dolphin, and Cuvier's beaked whale in the eastern tropical Pacific. Panels show 3 sample years (1998 [end of a major El Niño], 1999 [La Niña], and 2000 [ENSO-neutral]), the multi-year average, and $90 \%$ confidence limits. Dots are observed sighting locations for each time period. Taxonomic names as in Table 1 

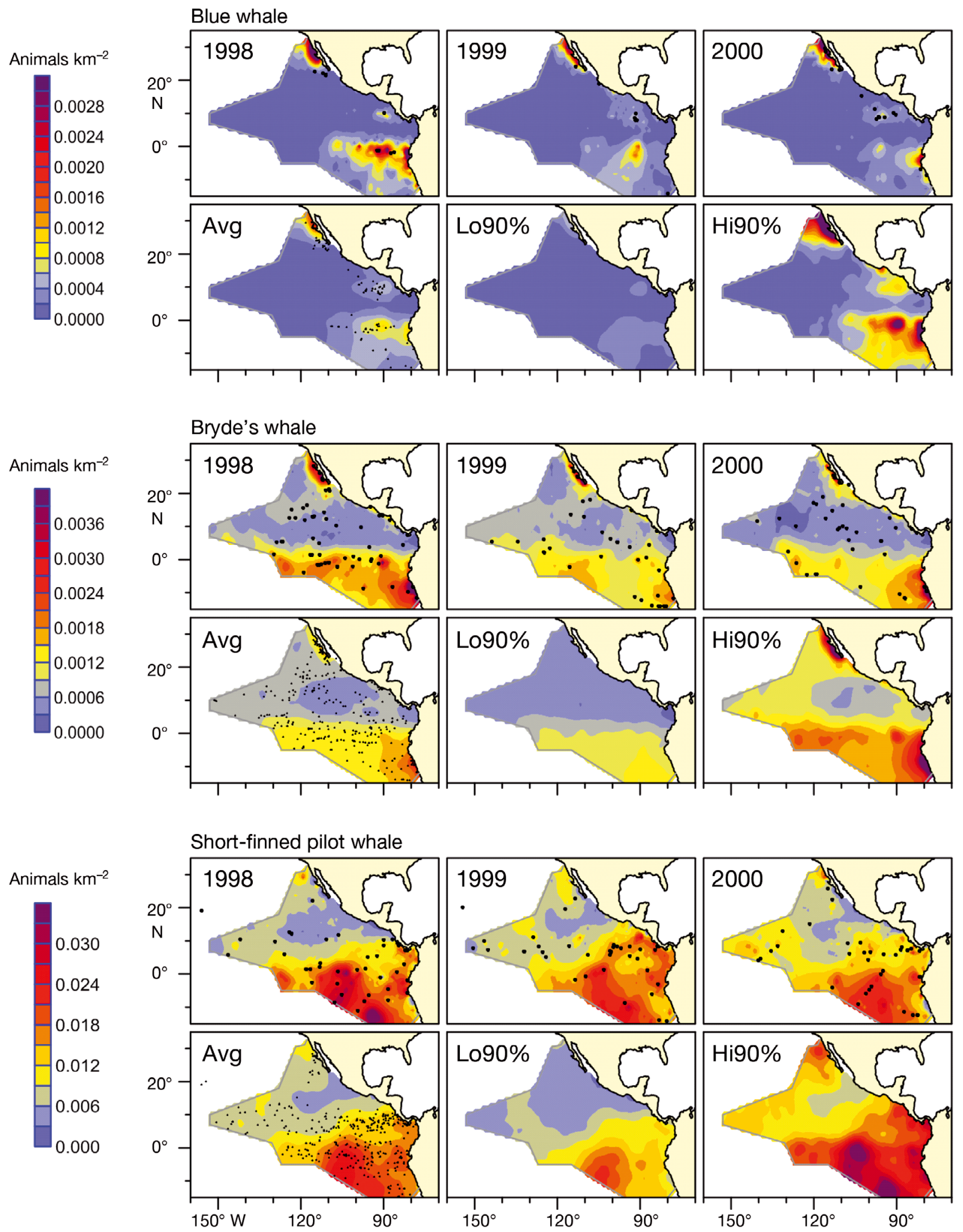

Fig. 8. Modeled species densities for blue whale, Bryde's whale, and short-finned pilot whale in the eastern tropical Pacific. Panels show 3 sample years (1998 [end of a major El Niño], 1999 [La Niña], and 2000 [ENSO-neutral]), the multi-year average, and $90 \%$ confidence limits. Dots are observed sighting locations for each time period. Taxonomic names as in Table 1 

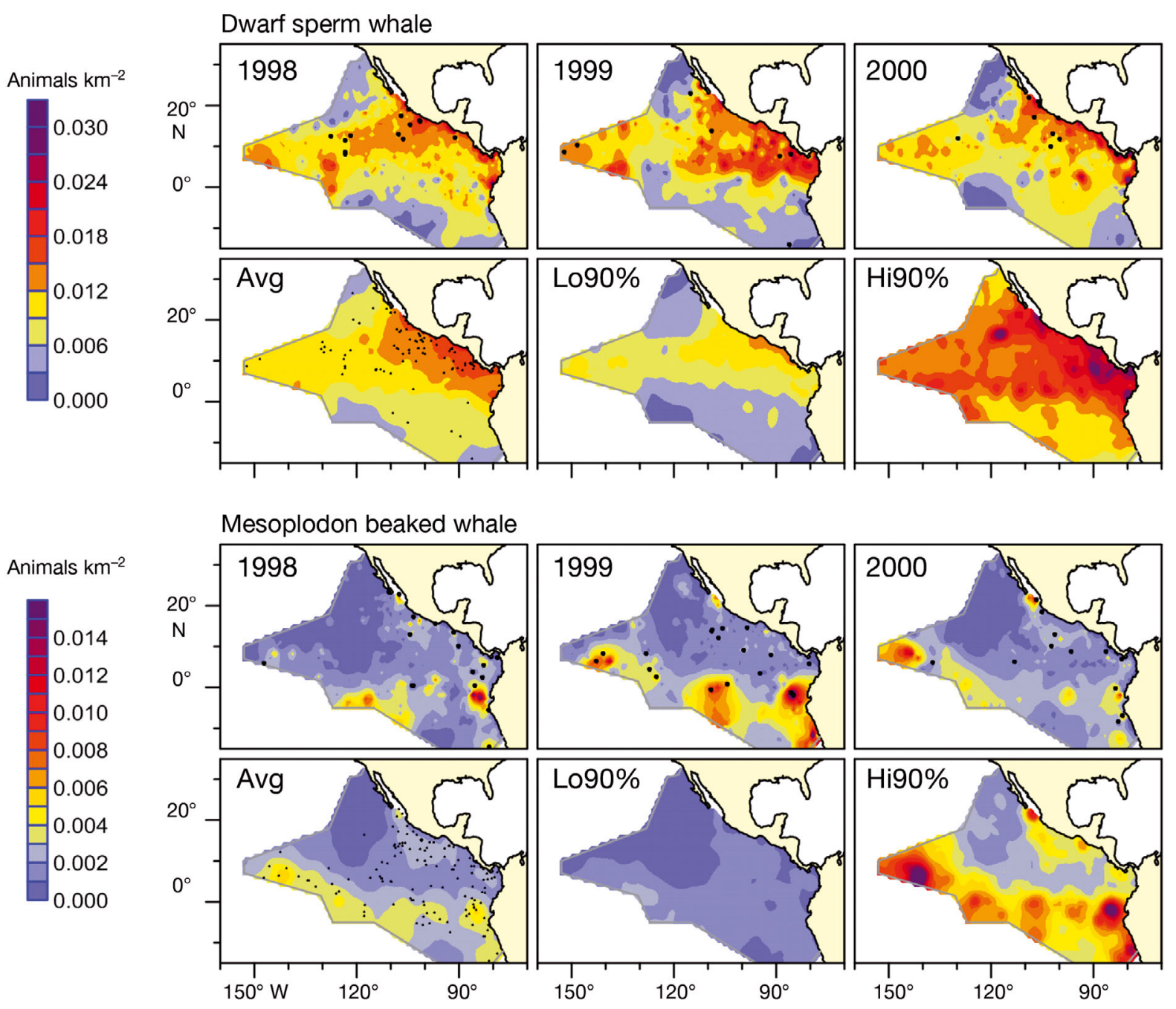

Fig. 9. Modeled species densities for dwarf sperm whale and Mesoplodon beaked whales in the eastern tropical Pacific. Panels show 3 sample years (1998 [end of a major El Niño], 1999 [La Niña], and 2000 [ENSO-neutral]), the multi-year average, and $90 \%$ confidence limits. Dots are observed sighting locations for each time period. Taxonomic names as in Table 1

temporal variation of each species. The model-based densities are currently accessible within a webbased interface that allows end-users to estimate average cetacean densities (and uncertainty therein) within any user-specified polygon (see Best et al. 2012, this Theme Section). This system has already been successfully used by the United States Navy, the National Marine Fisheries Service's Southwest Region, and other users to assist in planning, evaluation, and mitigation of potential impacts of various marine activities on cetaceans.

While our models represent a significant improvement over the previous, uniform-density estimates from broad-scale line-transect surveys, a logical next step in model development would be to identify methods of near real-time density predictions based on current or projected oceanographic conditions. In particular, seasonal changes cannot presently be modeled because rough weather conditions during winter/spring prevent surveys similar to those conducted in summer/fall. Research by Becker (2007) suggests that summer/fall models may have the potential to capture seasonal variability in addition to interannual variability, but such models will require the input of near real-time oceanographic data. Recent advances in processing and integrating remotely sensed data, ship reports, buoy data, and ocean circulation models to develop near real-time or forecast models (see Becker et al. 2012, this Theme Section) provide a foundation for such dynamic models. It may also be possible to develop analytical methods for incorporating alternative data types, 
such as small-scale line-transect survey, tagging, opportunistic, and acoustic data, into the development and validation of cetacean-habitat models. Currently, the models are based on large-scale line-transect surveys that are limited by weather, funding, and logistics. Expansion of the models to include alternative data types would help overcome some of these limitations. For example, tagging data and passive acoustic data could be useful in exploring seasonal distribution patterns and developing migration models for large whales.

Lastly, the present models only included habitat variables derived from physical and biological oceanographic data relating to primary producers, and it is unknown whether models could be improved through inclusion of indices related to the abundance of cetacean prey. Echosounder data are available for most cruises and have been looked at to evaluate patterns of overall dolphin distribution and abundance in the ETP (Fiedler et al. 1998); however, the data have not yet been fully processed for all surveys. Prey abundance indices have also been explored based on manta net and bongo net tow data collected during many of the surveys (Vilchis \& Ballance 2005), and future models might be able to include such prey indices as predictors.

Acknowledgements. This project was funded by the Strategic Environmental Research and Development Program (SERDP) and by the National Oceanic and Atmospheric Administration (NOAA). Initial funding for cetacean habitat modeling was provided by the United States Navy's Office of Naval Operations (N45), and we particularly thank Frank Stone and Ernie Young for their early support of this project. The marine mammal survey data and oceanographic data used to model cetacean density were collected by a large dedicated team at the Protected Resources Division of NOAA's Southwest Fisheries Science Center. We particularly thank the cruise leaders, marine mammal observers, oceanographers, survey coordinators, ship's crew, and officers who have worked hard over the past 20 yr collecting the data that we use here. We thank Dave Foley for his assistance with the remotely sensed data acquisition, and Ray Smith for his thoughtful comments on the model results. Our project benefited greatly from our close collaboration with Ben Best, Andy Read, and Pat Halpin at Duke University. We thank Bill Perrin and 3 anonymous reviewers for their helpful comments on earlier versions of this manuscript.

\section{LITERATURE CITED}

Barlow J (2003) Preliminary estimates of the abundance of cetaceans along the U.S. west coast: 1991-2001. Administrative Report LJ-03-03, NOAA NMFS Southwest Fisheries Science Center, La Jolla, CA

Barlow J, Forney KA (2007) Abundance and density of cetaceans in the California Current Ecosystem. Fish Bull 105: $509-526$
Barlow J, Ferguson MC, Becker EA, Redfern JV and others (2009) Predictive modeling of cetacean densities in the eastern Pacific Ocean. NOAA Tech Memo NMFSSWFSC 444. NOAA, La Jolla, CA

Becker EA (2007) Predicting seasonal patterns of California cetacean density based on remotely sensed environmental data. PhD dissertation, University of California, Santa Barbara, CA

> Becker EA, Forney KA, Ferguson MC, Foley DG, Smith RC, Barlow J, Redfern JV (2010) Comparing California Current cetacean-habitat models developed using in situ and remotely sensed sea surface temperature data. Mar Ecol Prog Ser 413:163-183

> Becker EA, Foley DG, Forney KA, Barlow J, Redfern JV, Gentemann CL (2012) Forecasting cetacean abundance patterns to enhance management decisions. Endang Species Res 16:97-112

Buckland ST, Anderson DR, Burnham KP, Laake JL, Borchers DL, Thomas L (2001) Introduction to distance sampling: estimating abundance of biological populations. Oxford University Press, New York, NY

Burnham KP, Anderson DR (1998) Model selection and inference: a practical information-theoretic approach. Springer-Verlag, New York, NY

Carton JA, Chepurin G, Cao X, Giese BS (2000) A simple ocean data assimilation analysis of the global upper ocean 1950-1995, Part 1: methodology. J Phys Oceanogr 30:294-309

Ferguson MC, Barlow J (2001) Spatial distribution and density of cetaceans in the eastern tropical Pacific Ocean based on summer/fall research vessel surveys in 1986-96. Administrative Report LJ-01-04, NOAA NMFS Southwest Fisheries Science Center, La Jolla, CA

Ferguson MC, Barlow J, Fiedler P, Reilly SB, Gerrodette T (2006a) Spatial models of delphinid (family Delphinidae) encounter rate and group size in the eastern tropical Pacific Ocean. Ecol Model 193:645-662

Ferguson MC, Barlow J, Reilly SB, Gerrodette T (2006b) Predicting Cuvier's (Ziphius cavirostris) and Mesoplodon beaked whale population density from habitat characteristics in the eastern tropical Pacific Ocean. J Cetacean Res Manag 7:287-299

- Fiedler PC, Talley LD (2006) Hydrography of the eastern tropical Pacific: a review. Prog Oceanogr 69:143-180

Fiedler PC, Barlow J, Gerrodette T (1998) Dolphin prey abundance determined from acoustic backscatter data in eastern Pacific surveys. Fish Bull 96:237-247

Forney KA (1997) Patterns of variability and environmental models of relative abundance for California cetaceans. $\mathrm{PhD}$ dissertation, University of California, San Diego, CA

$>$ Forney KA (2000) Environmental models of cetacean abundance: reducing uncertainty in population trends. Conserv Biol 14:1271-1286

Gerrodette T, Forcada J (2005) Non-recovery of two spotted and spinner dolphin populations in the eastern tropical Pacific Ocean. Mar Ecol Prog Ser 291:1-21

Hamilton TA, Redfern JV, Barlow J, Ballance LT and others (2009) Atlas of cetacean sightings from Southwest Fisheries Science Center cetacean ecosystem surveys: 19862005. NOAA Tech Memo NMFS-SWFSC 440. NOAA, La Jolla, CA

Hammond P, Berggren P, Benke H, Borchers D and others (2002) Abundance of harbour porpoise and other cetaceans in the North Sea and adjacent waters. J Appl Ecol 39:361-376 
Hastie TJ, Tibshirani RJ (1990) Generalized additive models. Monographs on applied statistics and applied probability. 43. Chapman \& Hall/CRC, Boca Raton, FL

Hedley SL, Buckland ST, Borchers DL (1999) Spatial modelling from line transect data. J Cetacean Res Manag 1: 255-264

Holm-Hansen O, Lorenzen CJ, Holmes RW, Strickland JD (1965) Fluorometric determination of chlorophyll. J Cons Int Explor Mer 30:3-15

> Jaquet N, Whitehead H, Lewis M (1996) Coherence between 19th century sperm whale distributions and satellite-derived pigments in the tropical Pacific. Mar Ecol Prog Ser 145:1-10

Kim YJ, Gu C (2004) Smoothing spline Gaussian regression: more scalable computation via efficient approximation. J R Stat Soc, B 66:337-356

Longhurst AR (2007) Ecological geography of the sea, 2nd edn. Elsevier Academic Press, Amsterdam

Monterey GI, Levitus S (1997) Seasonal variability of mixed layer depth for the World Ocean. NOAA NESDIS Atlas 14, US Government Printing Office, Washington, DC

Moore SE, Watkins WA, Daher MA, Davies JR, Dahlheim ME (2002) Blue whale habitat associations in the northwest Pacific: analysis of remotely-sensed data using a Geographic Information System. Oceanography 15: 20-25

Philbrick VA, Fiedler PC, Fluty JT, Reilly SB (2001) Report of oceanographic studies conducted during the 2000 Eastern Tropical Pacific Ocean survey on the research vessels David Starr Jordan and McArthur. NOAA Tech Memo NMFS-SWFSC 309. NOAA, La Jolla, CA

Philbrick VA, Fiedler PC, Ballance LT, Demer DA (2003) Report of ecosystem studies conducted during the 2001 Oregon, California and Washington (ORCAWALE) marine mammal survey on the research vessels David Starr Jordan and McArthur. NOAA Tech Memo NMFSSWFSC 349. NOAA, La Jolla, CA

Pitman RL, Lynn MS (2001) Biological observations of an unidentified mesoplodont whale in the eastern tropical

Editorial responsibility: Mark Baumgartner, Woods Hole, Massachusetts, USA
Pacific and probable identity: Mesoplodon peruvianus. Mar Mamm Sci 17:648-657

- Redfern JV, Ferguson MC, Becker EA, Hyrenbach KD and others (2006) Techniques for cetacean-habitat modeling: a review. Mar Ecol Prog Ser 310:271-295

Redfern JV, Barlow J, Ballance LT, Gerrodette T, Becker EA (2008) Absence of scale dependence in dolphin-habitat models for the eastern tropical Pacific Ocean. Mar Ecol Prog Ser 363:1-14

Smith RJ (1993) Logarithmic transformation bias in allometry. Am J Phys Anthropol 90:215-228

Smith RC, Dustan P, Au D, Baker KS, Dunlap EA (1986) Distribution of cetaceans and sea-surface chlorophyll concentrations in the California Current. Mar Biol 91: 385-402

Stevick PT, Allen J, Clapham PJ, Friday N and others (2003) North Atlantic humpback whale abundance and rate of increase four decades after protection from whaling. Mar Ecol Prog Ser 258:263-273

US Department of Commerce (2006) Two-minute Gridded Global Relief Data (ETOPO2v2). US Department of Commerce, National Oceanic and Atmospheric Administration, National Geophysical Data Center. Available at: www.ngdc.noaa.gov/mgg/fliers/06mgg01.html (accessed on 9 November 2006)

Vilchis LI, Ballance LT (2005) Developing indices of cetacean prey from manta and bongo net tows conducted in the northeastern and eastern tropical Pacific between 1987 and 2003. Administrative Report LJ-05012, NOAA NMFS Southwest Fisheries Science Center, La Jolla, CA

Wade PR, Gerrodette T (1993) Estimates of cetacean abundance and distribution in the eastern tropical Pacific. Rep Int Whal Comm 43:477-493

Wessel P, Smith WHF (1998) New, improved version of the Generic Mapping Tools, released. Eos Trans AGU 79:579 doi:10.1029/98EO00426

Wood SN (2006) Generalized additive models: an introduction with R. Chapman \& Hall/CRC, Boca Raton, FL

Submitted: January 16, 2011; Accepted: October 8, 2011 Proofs received from author(s): January 29, 2012 